\section{Cumplicidade e impunidade: uma análise pós-colonial do envolvimento do setor bancário na corrupção transnacional}

\author{
Isabella Chaves Nascimento e Cintia Rodrigues de Oliveira
}

\section{RESUMO}

Esta pesquisa aborda a corrupção, reconhecendo a importância das redes transnacionais informais na perpetuação da corrupção. O objetivo geral é compreender, sob a lente póscolonial, como a corrupção se constitui um fenômeno transnacional. Realizamos uma pesquisa qualitativa, com a análise de documentos sobre casos de corrupção envolvendo um grande banco internacional: o HSBC Holdings Plc. O material empírico foi extraído da organização International Consortium of Investigative Journalists (IClJ) e do jornal britânico The Guardian, sendo submetido à análise temática. O mapa temático final destaca dois temas que desvelam as relações coloniais: a cumplicidade dos agentes do sistema financeiro com os infratores e a impunidade do colonizador com esses mesmos agentes. Os resultados apontam para um padrão histórico de leniência e conivência do banco com criminosos, com diversos processos acusatórios encerrados com acordos, resumidos às multas que, por maiores que fossem em relação às práticas da justiça até então, não representavam sanções que inibissem as eventuais reincidências.

Palavras-chave: corrupção; pós-colonialismo; corporações.

Complicity and impunity: an analysis of banking sector's involvement in transnational corruption

\section{ABSTRACT}

This research approaches corruption, recognizing the importance of informal transnational networks in perpetuating corruption. The general objective is to understand, under the postcolonial lens, how corruption is a transnational phenomenon. We conducted a qualitative research, analyzing documents on corruption cases involving a large international bank: HSBC Holdings Plc. The empirical material was extracted from the organization International Consortium of Investigative Journalists (ICIJ) and the British newspaper The Guardian, and it was submitted to the thematic analysis. The final thematic map highlights two themes that reveal colonial relations: the complicity of agents in the financial system with offenders; and the impunity of the colonizer with these same agents. The results point to a historical pattern of leniency and connivance between the Bank and criminals, with several accusatory processes closed with agreements, summarized in fines that, no matter how large they were in relation to the practices of justice until then, it did not represent sanctions that would inhibit any possible recurrences.

Keywords: corruption; post-colonialism; corporations.

Recebido em: 04/04/2020 Revisado em: 11/05/2020 Aprovado em: 13/07/2020

Check for updates

Isabella Chaves Nascimento (iD,

Universidade Federal de Uberlândia, Brasil

Mestre em Administração,

Universidade Federal de Uberlândia, Minas Gerais, Brasil

isa_nascimento@yahoo.com.br

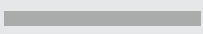

Cintia Rodrigues de Oliveira (iD,

Universidade Federal de Uberlândia, Brasil

Doutora em Administração, Fundação Getúlio Vargas, São Paulo, Brasil

cintia@ufu.br 


\section{Introdução}

A corrupção é um fenômeno recorrente na história de muitas nações, não podendo ser relacionado a um período específico, a um sistema econômico ou mesmo a um regime político. Sendo um fenômeno complexo, seu estudo exige considerar um conjunto mais amplo de fatores, tais como a concentração de poder político e econômico mundial, a profundidade das desigualdades sociais, a noção de interesse público, as instituições de direito, a tolerância da cultura às diferenças sociais, o distanciamento das elites e a falta de controle social (Pinto, 2011). Grandes atores na luta anticorrupção também foram os defensores da globalização econômica, como o Fundo Monetário Internacional (FMI), a Organização para Cooperação e Desenvolvimento Econômico (OCDE) e o Banco Mundial (Bratsis, 2014), apontando, desse modo, as soluções para o lado da demanda e não para o da oferta na equação global (Williams \& Beare, 1999).

Até a década de 1990, grande parte dos esforços contra a corrupção combatia a dimensão da demanda, limitando a questão ao contexto doméstico e institucional de suborno e corrupção pública (Bratsis, 2014; Cooley \& Sharman, 2015; Ware \& Noone, 2005; Williams \& Beare, 1999). Sendo assim, a corrupção assume um caráter transnacional quando envolve operações interconectadas por meio de redes estabelecidas para obscurecer a ilegalidade dessas transações (Christensen, 2011; Cooley \& Sharman, 2015).

As redes incluem, entre outros, empresas multinacionais, instituições financeiras, empresas offshore, operadores e corretores, que se tornaram cúmplices, ativa ou passivamente, ao criarem para essas transações uma fachada de conformidade com as normas e leis internacionais (Cooley \& Sharman, 2015), constituindo incentivos do lado da oferta, ao disponibilizar uma base operacional para lavagem do dinheiro (Christensen, 2011). E é a esse contexto que se associa a cumplicidade ocidental, pois a maioria das instituições não se encontra em países periféricos, mas nos centros financeiros europeus e estadunidenses ou em paraísos fiscais (Christensen, 2011; Cooley \& Sharman, 2015, 2017).

A questão geográfica da corrupção, cuja incidência é, normalmente, associada a países periféricos, é criticada por autores que defendem a visibilidade da atuação dessas redes transnacionais, seus incentivos e concessões, que representam, ao lado da própria oferta, uma forma de cumplicidade dos países do primeiro mundo, a qual não pode ser ignorada ao explicar a perpetuação do fenômeno (Bratsis, 2014; Christensen, 2011; Cooley \& Sharman, 2015; Platt, 2017). Uma das origens desse viés estaria associada aos próprios rankings de corrupção, dentre eles, o mais conhecido e criticado é o Corruption Perception Index (CPI - Índice de Percepção da Corrupção) desenvolvido pela Organização Não Governamental (ONG) Transparency International (Transparência Internacional) e publicado desde 1995 (Bratsis, 2014).

Nosso argumento vai ao encontro de Watson (2016, p. 30) quanto à ideia de que "o projeto colonial incorporou uma campanha contínua de séculos para aniquilar, definir, subordinar e excluir o nativo, e um arsenal de ferramentas 
foi aplicado para esses fins", porém, nesta pesquisa, nosso olhar vai em direção à ideia de um projeto colonial para a manutenção de um sistema capitalista em sua forma mais exploradora. Além disso, esta pesquisa analisa a presença de elementos coloniais de exploração nas dinâmicas exercidas por corporações financeiras multinacionais envolvidas em esquemas ilícitos, especialmente de corrupção, propondo-se a responder a seguinte questão: como a corrupção transnacional se associa ao projeto colonial a partir da perspectiva pós-colonialista? Nosso objetivo é compreender, sob a lente pós-colonial, como a corrupção se constitui em um fenômeno transnacional, utilizando como estudo de caso um grande banco internacional, o HSBC. A pesquisa é qualitativa, do tipo documental, com a análise temática de documentos e reportagens publicadas em jornais.

A possibilidade de contribuição teórica para os estudos organizacionais sobre corrupção se dá pela utilização de uma abordagem distinta da versão funcionalista recorrente nas ciências sociais (Lambsdorff \& Schulze, 2015). Vale ressaltar que a adoção dessa perspectiva nos permitiu vislumbrar que a corrupção sistêmica é produto da expansão global dos sistemas funcionais, não se definindo apenas pelas particularidades históricas de uma região; logo, países fora do Norte Global não são portadores de uma inferioridade nativa que os condena a uma corrupção fatal. A proposta deste estudo vai ao encontro da necessidade de ampliar a compreensão sobre os esquemas de corrupção, cujo combate é essencial para o processo de legitimação da democracia. O escopo da pesquisa pretende, ao se aprofundar sobre o caso de uma organização transnacional envolvida em escândalos financeiros, identificar os interesses que sustentam uma subjetividade internacional, os quais, tal como sugerido por Banerjee (2008), permitem ou, até mesmo, incentivam a corrupção, segundo conveniências próprias, indiferente à vida ou morte dos "damnés de la terre".

O artigo está estruturado da seguinte forma: depois dessa introdução, apresentamos a revisão da literatura sobre corrupção e a vertente pós-colonial; após, descrevemos os procedimentos metodológicos; em seguida apresentamos os resultados da pesquisa; por fim, apresentamos as considerações finais.

\section{Corrupção transnacional}

Corrupção e crime global estão intimamente conectados, visto que contrabando, tráfico de armas e drogas, lavagem de dinheiro, terrorismo e tantos outros seriam impraticáveis sem o envolvimento de funcionários corruptos nas alfândegas, agências financeiras, prestadores de serviço ou policiais (Christensen, 2011; Sampson, 2010; Shelley, 2005). Pelas características de ameaça à segurança e desrespeito às fronteiras, a corrupção e o crime se tornaram objetos de medidas internacionais de controle e mitigação. Governos recebem incentivos para se engajarem nessa luta, como empréstimos mais baratos, melhores ratings (avaliações) de crédito e promessas de entrada em organismos internacionais, bem como condicionalidades ou, até mesmo, sanções por negligenciarem as orientações dos acordos (Sampson, 2010). 
A Transparency International (2009) e o World Bank Independent Evaluation Group (2006) adotam uma visão realista ao definir a corrupção pela utilização de recursos públicos para ganhos privados, na mesma direção de Huntington (1975, p.72), para quem a corrupção é "o comportamento de autoridades públicas que se desviam de normas aceitas a fim de servir a interesses particulares", e de Silva (1994, p. 21), que afirma que corrupção é: "desvio de um padrão de conduta institucionalizado que se caracteriza principalmente pela utilização do público pelo privado com um manifesto propósito de favorecimento pessoal ou grupal", e também de Batabyal e Chowdhury (2015), que definem a corrupção como o abuso do poder confiado a alguém para a obtenção de ganhos privados, por exemplo, do governo para a obtenção de renda extra através do uso de serviços públicos.

A participação de agentes públicos também é relacionada na definição de corrupção transnacional, aquela cujo esquema envolve agentes públicos e do setor privado, ultrapassando as fronteiras entre países (Ware \& Noone, 2005) e constituindo redes que facilitam o financiamento ilícito transfronteiriço, a ocultação dos fluxos legais e ilegais de capital e a globalização de capitalistas através de múltiplas reivindicações de residência e cidadania (Cooley \& Sharman, 2017).

Além da questão econômica, a corrupção tem uma íntima ligação com aspectos políticos. Regimes democráticos podem oferecer diversos incentivos à corrupção, dependendo da forma como os processos eleitorais e legislativos são organizados e dos métodos de financiamento de campanhas estabelecidos (Carrington, 2007; Rose-Ackerman, 1996). Por outro lado, o extremo autoritarismo, domínio de oligarquias ou mudanças abruptas de regime, como o colapso da União Soviética e as disputas de poder na África pós-colonial, também representam terrenos férteis para corruptos (Platt, 2017). A corrupção surge em torno daqueles que estão em posições privilegiadas, bem como em função da fragilidade do sistema democrático naquele momento e como resultado de um cálculo econômico-racional feito por aqueles que têm suficiente poder discricionário e que acreditam na inoperância da lei nesses casos (Montigny, 2015).

O comportamento corrupto algumas vezes é justificado pela invocação de um padrão moral duplo, tendo em vista que as leis do país de destino são ignoradas quanto comparadas com as leis do país de origem ou, ainda, pelo argumento de obrigações com seus acionistas e funcionários em detrimento da preocupação com os cidadãos do país onde será realizado o negócio. Existem também as alegações de que pagamentos são feitos para evitar que uma empresa menos competente obtenha o contrato, supostamente beneficiando o país anfitrião e que os pagamentos sejam aceitáveis, pois são parte da cultura de se realizarem negócios na localidade "como uma resposta, ainda que desagradável, à fraqueza e venalidade dos governos" (Rose-Ackerman, 1996, p. 1891).

Essa lacuna entre os discursos corporativos e a prática resultam no que Sikka (2010, p. 165) denomina de "hipocrisia organizada", na qual corporações desenvolvem duas culturas: uma que promete conduta ética para o público externo e outra, aceita internamente, na qual práticas organizacionais são voltadas para a ampliação dos lucros a despeito de serem antiéticas. As 
percepções de multinacionais sobre a corrupção estão normalmente refletidas nos seus discursos de Responsabilidade Social Corporativa (RSC) (Dion, 2013), o que acaba por lhes fornecer um sentido duvidoso, seja por formarem uma cultura esquizofrênica (com dois universos morais, um aceitando a corrupção e o outro seguindo a RSC), seja por assumir esse relativismo ético apontado por Rose-Ackerman (2002), no qual a corrupção passa a ser considerada uma questão cultural e, portanto, particular daquela localidade.

O combate à corrupção passa pela compreensão dos sistemas de incentivo que moldam tanto o lado da demanda (agentes públicos) quanto o lado da oferta (agentes privados). O lado da demanda é conhecido pela definição da ONG Transparência Internacional como abuso de poder concedido para ganho pessoal, remetendo aos interesses das elites políticas, mas também aos riscos e opacidade do ambiente regulatório para os negócios (Bratsis, 2014). Por sua vez, o lado da oferta é bem menos questionado, pois o pagamento de suborno e a lavagem de dinheiro raramente são criminalizados, paraísos fiscais continuam protegendo o sigilo bancário e uma rede de atores internacionais, com agentes do sistema financeiro, permite que traficantes e corruptos sigam negociando (Christensen, 2011; Cooley \& Sharman, 2015, 2017; Platt, 2017).

Eventos como a crise financeira mundial de 2008 ressaltam os desafios da questão por trás da "opacidade, da supervisão regulatória insuficiente e dos conflitos de interesse em algumas partes da economia" (Transparency International, 2009, p,17). O setor privado é parte chave da dinâmica da corrupção transnacional, seja por meio do suborno de políticos ou partidos políticos de alto escalão; ou ainda pelo suborno de funcionários públicos de baixo nível para agilização de rotinas como desembaraço aduaneiro e licenciamentos, ou uso de relacionamentos pessoais ou familiares para obter contratos públicos privilegiados (Transparency International, 2009).

Ainda do lado da oferta, empresas multinacionais são responsáveis por estruturar arranjos complexos com o intuito de manter uma fachada em conformidade com os padrões internacionais anticorrupção, mas, passiva ou ativamente, perpetuam práticas que permitem às elites políticas locais acumularem fortunas à custa dos países por eles governados. Mesmo nos casos de cleptocracias - corrupção de larga escala realizada por governantes e seus familiares - que não necessariamente envolvem propinas e subornos de empresas estrangeiras, quase sempre se encontram aspectos transnacionais envolvendo a movimentação e a lavagem do dinheiro (Cooley \& Sharman, 2015).

Nesses arranjos transnacionais, o sistema financeiro internacional é um ator-chave em grande parte das operações que viabilizam a corrupção transnacional (Platt, 2017). Os fornecedores de serviços financeiros disponibilizam as contas e as estruturas empresariais que permitem a circulação do dinheiro oriundo dessas transações e aqueles inscritos em jurisdições menos rigorosas com relação à identidade e ao propósito das contas e operações, sendo conhecidos como "paraísos fiscais", os quais têm uma parcela considerável de responsabilidade (Christensen, 2011; Cooley \& Sharman, 2015; Platt, 2017). 
Apesar de não ser, em essência, prejudicial, o sigilo bancário permite a conversão de fundos ilícitos por criminosos, tornando os atores do setor bancário cúmplices no processo. Assim, para interromper esses padrões, as autoridades suíças precisariam repensar tanto a legislação que envolve o sigilo bancário, quanto a questão da criminalização da lavagem de dinheiro (Carlin \& Lokanan, 2018). O relacionamento estreito entre lavagem de dinheiro e padrões de comportamento no setor bancário suíço foram citados por Carlin e Lokanan (2018) como práticas simbólicas ritualizadas que modelam e influenciam as ações dos agentes, como a (i) normalização da corrupção e lavagem de dinheiro; (ii) desgaste da reputação suíça e do seu setor bancário; (iii) acusações de outros atores e negação de envolvimento; (iv) declarações de "suposto" arrependimento e; (v) críticas às leis de segredo bancário de forma geral.

A comunidade internacional reconhece que a corrupção se espalhou globalmente e autores sugerem que, talvez, um dos seus principais suportes seja a "conspiração de silêncio" (Ware \& Noone, 2005, p. 38) entre as multinacionais pagadoras de propina e os agentes governamentais de alto escalão que controlam os mecanismos institucionais que poderiam coibir tais práticas. Por anos, a corrupção foi considerada pela comunidade internacional como uma questão doméstica dos países atingidos, tendo sido somente a partir dos anos 1990 que o discurso de que não se tratava apenas de política interna, mas de desenvolvimento e pobreza, se tornou um consenso (Bratsis, 2014; Sampson, 2010; Ware \& Noone, 2005) e ativistas, instituições e homens de negócios levantaram a bandeira anticorrupção.

A suposta fragilidade dos sistemas de compliance de organizações financeiras pode ser atribuída a um processo intencional de negligência (Cooley \& Sharman, 2017), no qual sanções passíveis no contexto internacional, como multas, acordos de acusação diferida ou mecanismos de autorregulação não representam uma ameaça real ao negócio (Lord, 2014), devido ao seu poder financeiro e importância sistêmica (Hardouin, 2017). Ao mesmo tempo, o sistema de remuneração e bonificações do setor financeiro e sua alta lucratividade favorecem uma cultura de indiferença com as consequências sociais desses esquemas (Sikka, 2010). Assim, a impunidade, que poderia ser equacionada por medidas jurídico-legais mais eficientes, acaba por encontrar um contrapeso na complexa relação existente entre os interesses públicos e os privados (Sikka \& Lehman, 2015; Christensen, 2011; Carrington, 2007).

A impunidade, o silêncio e outros mecanismos contribuem para a normalização e a perpetuação da corrupção, pois estão inseridas nos processos de institucionalização (práticas de corrupção admitidas como parte da rotina), racionalização (uso de influências socialmente construídas para legitimação de atos corruptos); e socialização (estímulo para recém-chegados realizarem e aceitarem práticas corruptas), os quais atuam de forma conjunta (Ashfort \& Anand, 2003). Anand, Ashforth e Joshi (2004) observaram as seguintes táticas de racionalização utilizadas por envolvidos em corrupção: (i) negação de responsabilidade; (ii) negação do dano; (iii) negação da vítima; (iv) ponderações sociais; (v) apelo para lealdades elevadas e (vi) metáfora de equilíbrio, às quais Freitas e Medeiros (2018) adicionaram a "postura cínica" identificada em sua pesquisa. De Klerk (2017) traz a 
psicologia como uma abordagem complementar sobre a racionalização da corrupção, explorando motivos inconscientes para os atos corruptos.

A discussão sobre a atuação dos intermediários e dos paraísos fiscais não ignora a importância dos agentes corruptos como parte da demanda na equação da corrupção, mas lança questionamentos quanto à dicotomia convencional que associa países ricos àqueles honestos, e os pobres aos corruptos; ademais, esclarece que não é possível identificar uma distinção entre economias lícitas e ilícitas (Cooley \& Sharman, 2017). A corrupção pode ser abordada como um produto da dinâmica das organizações neoliberais, uma vez que os headquarters office dessas corporações não se encontram em países periféricos onde a corrupção é apontada, mas nos centros de poder econômico e nos paraísos fiscais (Cooley \& Sharman, 2015, 2017; Platt, 2017; Bratsis, 2014; Christensen, 2011).

\section{O olhar pós-colonial sobre a corrupção}

O marco cronológico do surgimento da Teoria Pós-colonial são os anos 1980, nos Estados Unidos da América e no Reino Unido, primeiramente nos estudos literários (Costa, 2013; Elam, 2019), com o pensamento centrado na contabilização dos impactos políticos, estéticos, econômicos, históricos e sociais do domínio colonial europeu no mundo. Mais tarde, no final do século XIX, começou a reorientar a crítica no campo dos estudos organizacionais críticos (Banerjee \& Prasad, 2008). O pensamento pós-colonial assumiu formas e intervenções variadas, porém, converge a ideia de que só é possível entender o mundo contemporâneo a partir da história do imperialismo e do domínio colonial, sugerindo ainda que "o mundo colonizado está no centro esquecido da modernidade global” (Elam, 2019, p.1).

A teoria pós-colonial assumiu múltiplas faces, como: as representações políticas e estéticas, o comprometimento com os impactos da globalização e da modernidade global; a política e a ética sob o poder imperial e seus efeitos; teorizações sobre formas de injustiça humana, do ambientalismo e dos direitos humanos (Elam, 2019), a consolidação do capital financeiro transnacional, a proliferação de redes planetárias, histórias diaspóricas, ameaça de catástrofes globais e o advento do pós-colonialismo (Vázquez-Arroyo, 2008). Esses temas revelam o engajamento intelectual do campo com a crítica e o questionamento de um universalismo sem história, o que influenciou sobremaneira o modo como entendemos os contextos sócio-históricos e culturais. A marca principal da crítica pós-colonial é a denúncia de oponentes e de projetos intelectuais institucionalizados (Almeida, Miglievich-Ribeiro, \& Gomes, 2013).

As lentes da crítica pós-colonial voltam-se para o passado como construção social, na busca de desconstruir as teorias que sustentam a modernidade e descobrir as vozes silenciadas nas formulações sobre outras perspectivas sociais. A crítica pós-colonial também se compromete com o presente, na desconstrução de práticas que preenchem as lacunas institucionais, e também com o futuro, pois é sobre ele que as ficções da modernidade são projetadas (Almeida, Miglievich-Ribeiro, \& Gomes, 2013, Prasad, 2016). Essa busca não acontece sem desafios, por exemplo, é 
preciso romper com silêncios do passado e com os discursos predominantes e hegemônicos, com a finalidade de recuperar histórias ocultas (Scott, 1999).

A perspectiva pós-colonial oferece uma alternativa para pesquisas que questionem os crimes corporativos, incluindo aqui a corrupção como uma prática planejada no contexto coorporativo, e não como um incidente ou desvio de conduta racionalmente justificada pelos benefícios prometidos pelo progresso (Medeiros, 2015). O pensamento pós-colonial compõe um arcabouço de interpretações para se analisarem os efeitos deixados pelo colonialismo nas antigas colônias, porém, são poucos e relativamente recentes os estudos que abordam o fenômeno da corrupção sob a perspectiva pós-colonial. A análise da corrupção sob a perspectiva histórica considera o tema um fenômeno global, inteligível apenas em seu contexto social, como observou Osoba (1996) no estudo sobre a Nigéria, onde a corrupção se tornou um modo de vida e o principal meio privado de acumulação do capital durante o período colonial e, na ausência de outros modelos, dominou a atividade política e a competição pós-independência.

Mulinge e Lesetedi (1998) defendem que, apesar de a corrupção ser uma das principais barreiras ao desenvolvimento econômico, social e político em diversas regiões do mundo, particularmente, na África Sub Saariana, os estudos que buscam explicar o enraizamento do fenômeno na região ignoram o papel do colonialismo na sua gênese e institucionalização. Existe um elo entre a incidência da corrupção e o contexto colonial como um todo e, em particular, com o período da pré-independência, no qual a utilização sistemática de incentivos materiais para compelir chefes e administradores locais a colaborarem no projeto colonial (Watson, 2016) transfigura-se, no período pós-colonial, nas práticas das elites políticas e burocráticas.

Esses elos são estabelecidos quando se analisa o efeito da monetarização na economia colonial pela imposição de taxas e as técnicas de "dividir para governar" utilizadas, principalmente, pela administração britânica. No primeiro caso, não era a questão das taxas em si, mas a forma como foi instituída a cobrança, estabelecendo-se um sistema de chefia que, caso não fosse colaborativa, seria substituída e, aceitando cooperar, seria motivada pela administração colonial, permitindo-se que ficassem, a título de riqueza pessoal, com parte do que fosse recolhido em impostos. Tal processo, pela ganância, cega os chefes locais em relação à situação da população em virtude dessas pesadas tributações. O segundo mecanismo encorajou a corrupção em diversas instâncias, podendo ser associado à questão da etnia rampante (tribalismo) e da propagação do nepotismo, com consequente avanço, sobre diversos países da região, da incompetência administrativa e da rapinagem (Mulinge, \& Lesetedi, 1998).

Gupta (1995) identificou no norte da Índia, nas notícias sobre a corrupção, os diferentes significados na representação do Estado entre os jornais ingleses e os locais. Enquanto nos primeiros a localização estrutural dos diálogos contempla as regiões centrais - os centros urbanos de capital, a alta política, a administração e a educação - os segundos delineiam as naturezas multicamadas e pluricêntricas do Estado, distinguindo-se entre um ente central e suas distintas representações burocráticas locais. As construções do Estado irão variar de acordo com a forma como os diferentes 
atores estão posicionados socialmente (Gupta, 1995), mesmo com todos os mecanismos para representá-lo como um ator coerente e unificado (Gupta, Nugent, \& Sreenath, 2015), como idealizado na visão eurocentrista.

No caso da Índia, a corrupção está enraizada nas formas de exploração econômica que foram legitimadas pelo Estado colonial e que continuaram a existir, mesmo após a independência e o estabelecimento do Estado constitucional pós-colonial, fato que Watson (2016) explica como a continuidade do projeto colonial. Assim, a difusão da corrupção reflete a continuação parcial de uma ordem social que o movimento anticolonial se propunha a transformar e, dessa contradição, se observa o quão instável se tornou o modelo de governança atual. Esse modelo relaciona corrupção a poder de uma forma pouco convencional, ao associar instituições do Estado inerentemente corruptas a patrocínio político, tolerando e, muitas vezes, celebrando a corrupção quando vista como possibilidade de empoderamento de castas inferiores que ascendem politicamente (Witsoe, 2011).

A necessidade de desconstruir a visão eurocêntrica também foi um argumento para De Maria (2005), que defende que o fracasso das intervenções anticorrupção em países da África se deve, em parte, à concepção ocidental de corrupção que domina o discurso político e, majoritariamente, pelo fato de que as prioridades são dadas aos interesses ocidentais e não aos africanos. A definição ocidental de corrupção desconsidera a complexidade das experiências culturais, interioriza os problemas africanos como seus consequentes e, destacado do contexto, padroniza o que, jurídica e moralmente, deverá ser considerado como corrupção pela comunidade internacional e, consequentemente, por organismos como ONGs, Nações Unidas, FMl e o Banco Mundial.

A segunda questão apontada pelo autor desvela o contexto neocolonial que se alastra pela região, partindo da premissa de que a fase inicial da exploração dos recursos africanos está sendo substituída pela transferência de ortodoxias ocidentais, particularmente, a democracia e a liberalização do comércio, que acabam por exigir que o Ocidente enfrente a corrupção africana (De Maria, 2005), não tanto pelas injustiças impostas à sociedade, mas pelos problemas estruturais que pode causar aos seus investimentos privados (Bratsis, 2014; Christensen, 2011; Campos, Lien, \& Pradhan, 1999). Soluções já conhecidas foram utilizadas, como a liberalização de mercado e as privatizações; entretanto, a análise empírica de programas de privatização em países africanos, ao longo dos últimos anos, evidencia o fracasso de tais medidas que nada fizeram além de manter esses países entre aqueles com os mais baixos índices nos rankings de corrupção (De Maria, 2005).

Ao analisar os institutos que fornecem informação para os indicadores de corrupção, como o CPI da Transparência Internacional, identifica-se a predominância dos interesses voltados para o ambiente de negócios, sendo pouco provável que o índice também não o seja (De Maria, 2008). Esse viés dos indicadores direciona o debate global para áreas que impõem custos aos negócios - o suborno e a propina no setor público -, ficando negligenciadas outras discussões que impõem prejuízo social e são associadas à corrupção, como evasões fiscais e lavagem de dinheiro corrupto em paraísos fiscais (Christensen, 2011). Nesse contexto, os indicadores terminam por reforçar 
"a percepção estereotipada da geografia da corrupção" (Christensen, 2011, p. 185), na qual os países africanos estão entre os mais corruptos, e paraísos fiscais ocupam posições confortáveis no ranking da corrupção, o que configura, assim, uma narrativa sobre a corrupção na África. Apata (2018) examina essa narrativa e argumenta que o discurso da corrupção na África é uma invenção ocidental que surgiu como uma construção pós-colonial, um discurso que distorceu e ignorou a verdadeira natureza do problema.

Com base na análise dos discursos anticorrupção no México, Coronado (2008) critica se existe realmente uma cultura de corrupção local ou se, de fato, há uma corrupção do conceito de cultura pelos interesses políticos e econômicos históricos por meio de construções ideológicas que mascaram o problema. O próprio reducionismo de definições amplas de corrupção, como o "uso indevido do poder público para benefício privado" deve ser desvelado porque "[...] é enganador ignorar as distinções entre práticas tratadas como iguais sob uma compreensão tão geral de corrupção. É o mesmo lutar contra a 'petty corruption' e a 'grand corruption'?" (Coronado, 2008, p. 5).

O discurso hegemônico dos organismos internacionais representa e mede a corrupção, definindo-a como o "risco país" dos que desejam se integrar à economia global ou, ainda, uma barreira à atratividade de investimentos estrangeiros e que, portanto, precisa ser tratada ou até mesmo erradicada. A suposição de que a corrupção faz parte da cultura transmite a sensação de que os países com alto risco têm um comportamento profundamente enraizado em sua consciência coletiva. Essa metáfora desloca o problema e obscurece formas reais de solucioná-lo ao ignorar os piores tipos de corrupção: aqueles que beneficiam os governantes e a elite local (Coronado, 2008).

Associações à questão intercultural foram fortemente influenciadas pelas dimensões de Geert Hofstede, segundo as quais a representação de atributos essencialistas configura uma oposição de negativo versus positivo, o que é facilmente convertida em Oriente versus Ocidente (Westwood, 2006). Essa abordagem, que associa as dimensões culturais à corrupção, tem características discursivas semelhantes aos rankings de corrupção internacional, visto que ambos se constituem como instrumentos que legitimam a autoridade com um regime discursivo de "verdade científica" (Coronado, 2008). Nos discursos analisados, com mídias de duas diferentes iniciativas anticorrupção no México, Coronado (2008) destaca o peso dado às práticas informais, principalmente, aquelas associadas a setores mais pobres da sociedade, ignorando, de forma sutil, os contextos de corrupção institucionalizada e sugerindo que estancar a corrupção significaria mudar o comportamento das pessoas comuns e não coibir práticas sistêmicas que lucram com as pressões globais do neoliberalismo contemporâneo.

A importância da perspectiva pós-colonial é ressaltada quando nos deparamos com o fato de que, aproximadamente, três quartos da população mundial teve sua vida moldada pela experiência colonial, sendo relativamente simples perceber a relevância desse fato nas esferas política e econômica, mas bem menos evidente quando nos referimos à influência geral sobre as percepções dos indivíduos comuns (Ashcroft, Griffiths, 
\& Tiffin, 2003). Embora as administrações coloniais tenham sido quase que inteiramente erradicadas e a maioria da periferia esteja politicamente organizada em Estados independentes, esses ainda vivem sob exploração e dominação euro-americana. A despeito das retóricas de "um mundo sem fronteiras" e "para todos", o que existe é uma nova forma de colonialismo global com raízes nas estruturas históricas do capitalismo, utilizando-se da racionalidade para atingir objetivos coloniais ainda atrelados ao desenvolvimento dos colonizadores (Banerjee \& Linstead, 2001), como, por exemplo, o silenciamento do subalterno (Spivak, 1988).

A teoria pós-colonial dirige uma crítica radical ao colonialismo, imperialismo e o neocolonialismo (Banerjee \& Prasad, 2008). Já a crítica pós-colonial, ao examinar questões de poder, economia, política, religião e cultura, e como esses elementos funcionam em relação ao controle da hegemonia colonial dos ocidentais sobre os colonizados, faz um interrogatório crítico das práticas, modalidades e projetos pelos quais a modernidade se inseriu e alterou as vidas dos colonizados. Trata-se de um movimento que prioriza o questionamento sistemático das suposições epistêmicas e políticas que sustentaram e autorizaram a construção das concepções universalistas (Vázquez-Arroyo, 2008).

Corporações multinacionais associadas a governantes, organismos supranacionais e agências internacionais contribuem para a violenta privatização da soberania, sobrepondo seus interesses econômicos, atrelados ao poder militar que já caracterizava o projeto colonial, sob uma nova configuração imperialista e neoliberal (Banerjee, 2008a). Essas formas contemporâneas de acumulação organizacional, muitas vezes, com a conivência das elites políticas locais, "envolvem espoliação e subjugação da vida ao poder da morte" (Banerjee, 2008a, p.1541), caracterizando um necrocapitalismo, exemplificado na violência de indústrias extrativistas em países periféricos e na privatização da guerra, dos conflitos armados e da segurança.

\section{- Procedimentos metodológicos}

Ao situarmos a corrupção transnacional como parte do lado sombrio das organizações, buscamos perspectivas que se afastem da visão positivista voltada para performance organizacional e se orientem por uma visão que questione práticas e saberes institucionalizados (Adler, Forbes, \& Willmott, 2007). Esta pesquisa se inscreve no domínio dos Estudos Dialógicos (Alvesson \& Deetz, 1999), sendo um estudo qualitativo de um caso único, cujo método de procedimento é a pesquisa documental. A construção do corpus de pesquisa implica na "escolha sistemática de um racional alternativo" (Bauer \& Aarts, 2002, p. 39), invariavelmente arbitrário, para seleção de representações significantes da vida social que será analisada. Como critérios, optamos pela análise em uma organização multinacional do setor bancário, o que permite o encontro com nosso contexto de corrupção transnacional. O segundo critério considerado foi que houvesse envolvimento com casos de corrupção nos últimos 10 anos, mesmo não sendo a organização o principal agente, pois esse quesito implica na disponibilização de material documental para a 
investigação. Por fim, julgamos importante que esse ilícito envolvesse, em alguma esfera, contextos de países do Sul global, dada a nossa intenção de analisar o fenômeno a partir das margens.

Iniciamos a seleção da organização a partir da lista cronológica de exemplos de bancos indiciados e processados desde a década de 1990 até 2015, a qual consta do relatório Banks and Dirt Money (Bancos e Dinheiro Sujo), da organização não governamental Global Witness (2015, p.11), que identifica, nominalmente, dezenove instituições (Riggs Bank, Barclay, RBS, HSBC, NatWest, UBS, Wachovia, Citibank, Abbey National, Coutts \& Co Bank, Credit Suisse, BNP Paribas, Standard Chatered, Bank of Tokyo Mitsubishi, JP Morgan, Bank of America, Lloyds, TSB, Commerzbank), das quais o HSBC aparece com o maior número de ocorrências, seguido pelo Barclay.

O banco britânico HSBC, além de um dos maiores bancos internacionais em ativos da atualidade, atendeu aos outros dois critérios. Quanto à participação recente em grandes escândalos de fraudes e crimes financeiros, destacam-se casos conhecidos, sendo: a maior multa aplicada a um agente individual por lavagem de dinheiro, USD 1.92 bilhão nos EUA, em 2012; o maior vazamento de dados bancários da história, que se refere à filial suíça, divulgado ao público em 2015 pelo Swiss Leaks (Ryle, Fitzgibbon, Cabra, Carvajal, Guevara, Hamilto, \& Stites, 2015); e o envolvimento com o escritório Mossack \& Fonseca, seu principal cliente bancário, no maior vazamento de informações de contas offshore divulgado, em 2016, pelo Panama Papers (IClJ, 2016). Por fim, o terceiro critério para seleção do HSBC como organização de análise foi atendido, visto que, nos últimos dois casos, encontram-se indícios de lavagem de dinheiro relacionada à corrupção de agentes brasileiros e de outros países do Sul, destacando-se, inclusive, envolvimento com a operação Lava Jato (IClJ, 2016).

A construção do corpus de pesquisa restringiu-se às fontes da pesquisa documental pelos critérios de cobertura jornalística de livre acesso/gratuita, internacionalmente reconhecida e com protagonismo jornalístico em algum dos casos envolvendo o HSBC. Assim, a organização International Consortium of Investigative Journalists (IClJ) e o jornal britânico The Guardian foram selecionados e as consultas realizadas nos respectivos websites, utilizando como palavras-chaves o termo HSBC combinado com "corruption", "corrupt" e "bribery", somando inicialmente 127 reportagens, as quais, após análise de aderência ao conteúdo e ao período de análise, resultaram em 55 reportagens (12 IClJ e 43 The Guardian) e em 208 laudas (92 IClJ e 116 The Guardian) para análise, com tradução nossa.

O material empírico foi submetido à análise temática (Braum \& Clarke, 2006), um método sugerido para identificar, analisar e reportar determinados padrões tratados como temas, em um corpus de pesquisa. Ao compreendermos que a identificação de temas envolve um constante movimento de ir e vir na análise dos textos, iniciamos pela (a) familiarização com os dados, antes de iniciar a codificação, procurando por significados, padrões e ideias que permeassem todo o material, e seguimos as demais etapas: (b) geração dos códigos iniciais, quando geramos a primeira lista de categorias com o objetivo de organizar os dados em grupos de significado 
(Tuckett, 2005). Dentre os vários tipos de codificação, ou seja, a marcação das unidades de análise ou registro (Krippendorf, 2004), a opção foi pelos segmentos de texto delimitados como parágrafos ou conjuntos de linhas com a mesma ideia central (Medeiros, 2013). A codificação foi realizada nos textos completos e não apenas nas partes de interesse, com suporte do software ATLAS.ti 8. Depois, a próxima etapa foi a (c) identificação dos temas, a partir da lista de códigos revisitada e seus respectivos segmentos de texto. Assim, reorientamos a análise para combinar os diferentes códigos em temas potenciais, gerando um mapa temático inicial com a utilização das funcionalidades de Code Group (agrupamento de família de códigos) e Network (redes) do ATLAS.ti 8, permitindo estabelecer, graficamente, as associações identificadas. Em seguida, demos continuidade com a (d) revisão dos temas: de forma iterativa, realizando a revisão do mapa temático construído até então, validando cada tema potencial em relação ao corpus como um todo. Além disso, refizemos a leitura dos textos e verificamos a necessidade de se corrigir, adicionar ou excluir algum código ou tema, consolidando-os até que o mapa expressasse a essência dos textos. Alguns temas surgiram e não se sustentaram ou foram englobados por outros que se mostraram mais consistentes na medida em que as comparações foram sendo realizadas, levando a dois temas finais revelados a partir de nove temas intermediários resultantes da associação de 42 categorias registradas (Figura 1). Em (e) definição e nomeação dos temas, realizamos o seguinte: como cada tema exprime um aspecto do corpus, para cada um deles conduzimos uma análise detalhada, tendo em mente tanto sua essência, quanto seu suporte teórico, bem como as associações que levariam às respostas que ele apresenta às questões e ao objetivo de pesquisa; por fim, compomos a $(\mathrm{f})$ elaboração do relatório: estruturamos a narrativa que apresenta o contexto e a análise, subsidiada com segmentos dos textos suficientes para ilustrar os temas intermediários e finais encontrados no corpus.

\section{Apresentação e análise dos dados}

Com base na perspectiva da corrupção transnacional, situamos os casos de envolvimento do HSBC como um elo importante nessa rede de intermediários, viabilizando transações corruptas ao mesmo tempo em que conecta e orienta seus clientes. A escolha do HSBC como ponto de análise da dinâmica da corrupção transnacional no setor financeiro não foi aleatória, visto que ele se encontra entre os bancos mais citados quando se fala de lavagem de dinheiro (Global Witness, 2015), demonstrando um comportamento ora leniente, ora proativo com ditadores africanos, traficantes de drogas latinoamericanos, terroristas árabes e tantos outros suspeitos internacionais por mais de uma década (Rushe \& Treanor, 2012).

Os temas que emergiram dessa análise estão presentes em um contexto de globalização, no qual tanto as corporações, quanto os contraventores estão posicionados internacionalmente e com poucas limitações legais que consigam restringir o fluxo e a ocultação de capital através das fronteiras. Em uma era digital, subornos podem ser pagos sem a entrega de "malas de 
dólares", utilizando-se de transferências e contratos eletrônicos por meio de intermediários em paraísos fiscais que protegem o sigilo bancário e ocultam os verdadeiros beneficiários de cada conta. A maioria desses centros offshore ou onshore não estão localizados onde está a corrupção "combatida", com seu legado de drenagem de riquezas e perpetuação da miséria, mas, sim, em países ocidentais desenvolvidos e em seus protetorados peninsulares.

A análise temática do material empírico foi direcionada pelo interesse em compreender como a corrupção transnacional se associa ao projeto colonial, a partir da perspectiva pós-colonial, tendo desvelado dois temas finais que sintetizam a associação entre a dinâmica da corrupção e o projeto colonial, expressos como a cumplicidade e a impunidade (Figura 1).

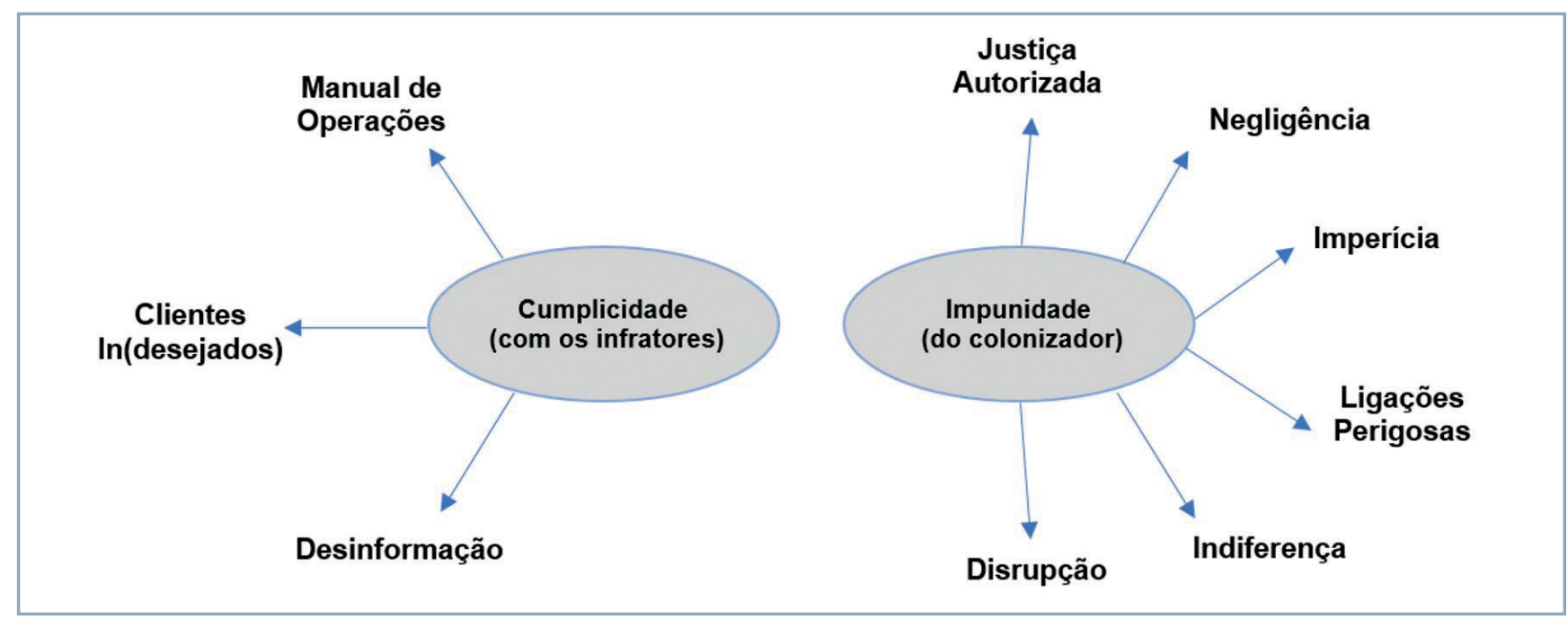

Figura 1: Mapa temático final

A opção pela análise temática se ancora na flexibilidade e, ao mesmo tempo, à estrutura do método, o que permite uma análise interpretativa dos textos sem a preocupação com quantificações. O mapa temático final (Figura 1) foi gerado a partir de nove temas intermediários, cada um deles associado a um padrão e a um conjunto de atores, sendo nomeados pela associação com seu conteúdo: manual de operações, clientes (in)desejados, desinformação, justiça autorizada, negligência, imperícia, ligações perigosas, indiferença e disrupção. Os nove temas intermediários, por sua vez, compreendem 42 categorias.

\section{Tema final 1: cumplicidade}

A acepção do termo cumplicidade remete à colaboração ao tomar parte em um delito ou crime e tal termo foi utilizado para nomear um dos temas principais encontrados nesta pesquisa. Essa definição expressa a associação entre os interesses econômicos e as estruturas que, antes, caracterizavam o projeto colonial (Banerjee, 2008a; Coronado, 2008; Watson, 2016; Apata, 2018) e, agora, dão forma ao neoliberalismo contemporâneo no discurso da globalização. Nesse novo formato de acumulação de capital, a corporação é um ator poderoso que, em conluio com "estados-nações, 
organismos supranacionais e agências internacionais, contribui para uma privatização necrocapitalista da soberania" (Banerjee, 2008a, p.1549) em um imperialismo sem colônias.

Nesse contexto, a cumplicidade do sistema financeiro com os infratores é um tema que permitiu compreender uma parte importante da dinâmica dos esquemas da corrupção transnacional, bem como identificar atores relevantes, evidenciando como corporações financeiras atuam em parceria com agentes corruptos de todos os níveis (Cooley \& Sharman, 2015). Esses podem incluir europeus afortunados, que evadem impostos por meio de empresas de fachada em paraísos fiscais, passando por traficantes, que suprimem pela violência ou pelo suborno os sistemas ao seu redor e, por fim, o alcance de políticos e elites corruptas que drenam a riqueza de países periféricos aos quais deveriam servir. $O$ tema final 1 agrupa três outros temas intermediários: manual de operações, clientes (in)desejados e desinformação.

Manual de operações compreende um conjunto de formas de atuação que permitem a compreensão dos padrões aceitos e praticados pelas instituições financeiras, particularmente, o banco HSBC, no conluio com os contraventores globais, conforme exposto a seguir.

A participação do HSBC nas fraudes e crimes refere-se às declarações e explicações que fazem ligação direta entre as atividades do HSBC como instituição, de forma intencional, com as potenciais transações ilícitas de seus clientes, sejam elas evasão fiscal, lavagem de dinheiro, corrupção, tráfico de armas, drogas ou diamantes, como ilustrado abaixo:

\begin{abstract}
Impulsionado pelo desejo de expandir seus negócios e aumentar a receita, o HSBC implementou intencionalmente programas, processos e controles criminalmente deficientes contra lavagem de dinheiro, que foram projetados para garantir que bilhões de dólares passariam por seus bancos sem serem detectados ou declarados. E foi exatamente isso que aconteceu", alega a ação, citando que os processos de due diligence nas agências bancárias mexicanas eram inexistentes ou fabricados, permitindo que indivíduos suspeitos depositassem centenas de milhares ou até milhões de dólares norte-americanos. (DART, 2016, p.2).
\end{abstract}

Redes financeiras para atender contraventores estabelecidas entre instituições do mercado financeiro (bancos, escritórios de advocacia, imobiliárias, operadores, outros) por meio de troca de informações e relacionamentos comerciais entre si, muitas vezes, entre diferentes jurisdições, para viabilizar transações de clientes que objetivam, particularmente, ocultar a verdadeira natureza dessas operações:

\begin{abstract}
Bancos como o HSBC criaram um sistema para enriquecer às custas da sociedade, ajudando na evasão fiscal e na lavagem de dinheiro", disse ele em uma entrevista concedida em julho de 2013 ao Der Spiegel [revista semanal de notícias alemã]. Ele disse que o HSBC tinha uma divisão para ajudar a ocultar identidades e transações de clientes. "Por exemplo, um banco pode introduzir empresas intermediárias, às vezes em vários níveis, e garantir que os negócios não sejam conduzidos pelas próprias contas do banco." (Hamilton, 2015, p.3).
\end{abstract}

Descumprimento consciente da legislação se refere às situações de desobediência intencional de legislação específica do mercado financeiro, com citação explícita de um descumprimento de norma pelas instituições (bancos, escritórios de advocacia, imobiliárias, outros) com a finalidade 
de autofavorecimento ou de seus clientes. As ações envolviam, por exemplo, manipulação retroativa ou destruição de informações de contas e documentos; não realização de due diligences e monitoramento adequado de PEPs (Politically Exposed Person) ou clientes corporativos que operam em localidades com maior fragilidade institucional; não observação de listas de pessoas bloqueadas pela OFAC (Office of Foreign Assets Control) ou jurisdições com sanções; não observância de procedimentos antilavagem de dinheiro (AML - Anti-Money Laundering); articulação entre instituições para manipulação de taxas interbancárias, entre outros, como apresentado no exemplo a seguir:

No caso "Operação Lava Jato" no Brasil, os promotores alegam que os funcionários da Mossack Fonseca destruíram e ocultaram documentos para mascarar o envolvimento do escritório de advocacia na lavagem de dinheiro. Um documento da polícia diz que, em um caso, um funcionário da filial da empresa no Brasil enviou um e-mail instruindo colegas de trabalho a esconderem registros envolvendo um cliente que pode ter sido alvo de uma investigação policial: "Não deixe nada. Vou salvá-los no meu carro ou na minha casa." (IClJ, 2016, p.14).

Orientação explícita sobre como subverter a legislação refere-se às situações nas quais houve, por parte da instituição financeira, descrição sobre providências ou melhores procedimentos a serem seguidos pelos clientes para viabilizar uma transação, em essência, ilícita, com garantias de segredo fornecidas pela instituição. Nesses casos, descrevem-se indicações para criações de empresas offshore nos casos em que a utilidade não é legítima, ou a realização de operações sigilosas envolvendo, por exemplo, lavagem de dinheiro.

As concisas notas vazadas mostram os clientes do HSBC aceitando passivamente fazer parte das novas estruturas depois que os banqueiros as propunham: "Explicado em detalhes como funciona a ESD; o cliente aceitou estabelecer uma nova empresa offshore para esse propósito e assinou toda a documentação necessária", mostra um registro para um joalheiro de Hatton Garden [rua de Londres conhecida pelas joalherias] com £15 milhões. (Leigh, Ball, Garside, \& Pegg, 2015d, p.2)

A questão do conhecimento de questões ilícitas associadas às operações dos clientes refere-se ao conhecimento, total ou parcial, por parte dos agentes do mercado financeiro, de que as atividades dos seus clientes, ou partes delas, estavam em desacordo com questões morais ou legais, seja por negociar com contraventores ou ditadores, evasão de impostos, lavagem de dinheiro, pagamentos ilegais etc.

O HSBC Private Bank, operando a partir da famosamente neutra Suíça, era um canal financeiro para operadores de negócios e criminosos que alimentavam e financiavam algumas das guerras mais sangrentas da África e a maioria dos negócios corruptos de armas. Para o HSBC, os homens e mulheres por trás desses conflitos eram clientes lucrativos; coletivamente, as contas de pessoas ligadas ao tráfico de armas e a contratos corruptos de armas, em pelo menos sete países africanos, mantiveram saldos em 2006 ou 2007 que totalizaram mais de USD 56 milhões. (Fitzgibbon \& Hamilton, 2015, p.1-2).

Baixos padrões de controle interno do banco também foram identificados como rotina nas operações das instituições, sendo a falta de conformidade nos processos internos do banco a causa primeira do descumprimento da lei, além de lacunas que facilitam a ocultação de patrimônio ou dificultam 
o rastreamento da origem/finalidade de fundos. Essas falhas envolvem, por exemplo, cadastros errados ou incompletos quanto às informações da conta, baixa capacitação da equipe interna em compliance, infraestrutura ou hierarquia da referida área deficitária e ineficiente para verificação adequada dos alertas internos, ausência de padronização nos controles entre as subsidiárias (gestão federada), entre outros.

\begin{abstract}
Normalmente, o departamento de conformidade e investigações é tratado como um filho adotivo indesejado. Os diretores de um banco veem a conformidade como uma despesa sem qualquer retorno. Os profissionais de conformidade são mal pagos, não qualificados e recebem pouco ou nenhum treinamento efetivo para detectar padrões criminosos." (Harding, Hopkins, \& Barr, 2017, p.3).
\end{abstract}

Os bancos atuam em redes como um dos principais intermediários, fato que dilui os custos de transação para os agentes corruptos ou facilita a realocação dos espólios (Cooley \& Sharman, 2017). Os intermediários conhecem os negócios de seus clientes e os auxiliam na ocultação do patrimônio reconhecidamente ilícito, seja ativamente, por meio das orientações em operações e investimentos, ou passivamente, ao ignorar alertas internos de compliance ou as recomendações normativas dos reguladores financeiros. Estes são impulsionados por um sistema de incentivos que, ao que tudo indica, faz parte da cultura dessas instituições (Carlin, \& Lokanan, 2018; Sikka, 2010), fazendo com que se sintam fora do alcance da lei (Sikka, 2008).

As práticas do sistema financeiro refletem a estratégia básica dos negócios, que é aumentar o valor para o acionista e gerar retorno sobre o capital, não promovendo a justiça social ou a moralidade, um discurso da modernidade (Elam, 2019). Questiona-se, assim, a partir da crítica pós-colonial, o discurso imperialista que cria expectativas de comportamento empresarial "socialmente responsável", o que acontecerá somente pela reestruturação na economia política vigente para que se possa repensar o papel das corporações na sociedade (Banerjee, 2008b).

Clientes (in)desejados refere-se à atuação de contraventores que utilizam o sistema financeiro como cúmplices para estruturar suas operações. Sem a participação dos bancos, escritórios de advocacia, imobiliárias e tantos outros, muitas dessas operações não seriam possíveis na proporção em que são realizadas. A lógica seria que tais clientes fossem "indesejados", dado o padrão de responsabilidade e compromisso socialmente esperado dessas instituições, mas o fato é que, para o sistema financeiro, esses clientes são "desejados". Essa constatação parte do princípio de que existe um custo e, portanto, um lucro associado à criação de uma empresa offshore ou à realização de uma transferência internacional e, tanto maior são as margens, quanto mais complexas ou sigilosas são as necessidades da operação. E, assim, a relação desses atores pode ser resumida a uma "questão de oportunidade e ganância" (Ware \& Noone, 2005, p.44) ou traduzida, simplesmente, como cumplicidade.

Corrupção política em países periféricos refere-se à descrição dos clientes corruptos que operam em países em desenvolvimento ou subdesenvolvidos, incluindo, nessa lista, políticos, seus familiares e agentes, cujo enriquecimento se deve ao contexto político em que estão inseridos e do qual se beneficiam: 
Regularmente chamado de "homem da mala" de Assad - termo para alguém utilizado para gerenciar ou mover receitas da corrupção - Makhlouf está na lista de sanções dos EUA por "beneficiar-se da corrupção síria" desde 2008, e na lista de sanções de toda União Europeia desde a guerra civil na Síria em 2011. Ele controla a maior companhia telefônica da Síria, bem como grande parte de seu sistema bancário, imóveis, lojas de departamentos e muito mais. Ele também é um importante financiador da rede de televisão al-Mayadeen, criada para concorrer com a bem conhecida al-Jazeera do Qatar. (Leigh et al., 2015e, p.1)

A atuação dos HNWI (High Net Worth Individuals) refere-se à descrição do estilo de vida, à história pessoal e de família, bem como ao relacionamento com bancos e outros agentes financeiros de pessoas classificadas como de alta renda, de forma geral, nem todos ligados a operações elíticas:

Von Opel, um importante doador do Partido Conservador citado nos arquivos do HSBC, é bisneto do empresário automotivo alemão Adam Opel. Ele tem lares no Reino Unido e uma esposa britânica, mas disse ao The Guardian que é residente suíço. Desde que se mudou para a Suíça quando criança, Von Opel tem sido um exilado de impostos, gerenciando sua fortuna a partir daí. Seu escritório disse que nenhuma das contas da Von Opel foi usada para fugir ou evitar impostos. Eles acrescentaram: "O Sr. Von Opel ... é um suíço e residente suíço desde 1973." (Leigh et al., 2015e, p.1)

Atuação de traficantes de drogas e armas refere-se à dinâmica do tráfico de drogas e seu envolvimento com o sistema financeiro, seja nas transações comerciais com usuários e outros traficantes, como de armas, ou nas relações com instituições financeiras locais e internacionais:

Um dos que receberam dinheiro em espécie e dólares foi Arturo del Tiempo Marques, um promotor imobiliário condenado em 2013 a sete anos de prisão na Espanha por contrabando de cocaína. Ele controlou até 19 contas HSBC contendo mais de USD 3 milhões. (Ryle et al., 2015, p.8)

A atuação de financiadores do terrorismo refere-se às operações de terroristas e seus financiadores, bem como ao seu envolvimento com o sistema financeiro, seja nas transações comerciais, no estabelecimento de operações ou nas relações com instituições financeiras locais e internacionais. Diferem-se da dinâmica dos traficantes de armas devido a sua orientação, em princípio, de ordem política e não somente monetária:

Os links dos clientes do HSBC com a Al Qaeda foram levantados publicamente pela primeira vez no relatório do Senado norte-americano de julho de 2012, citando uma suposta lista interna de benfeitores financeiros da AI Qaeda. O relatório do Senado disse que a lista veio à tona após uma busca nos escritórios bósnios da Benevolence International Foundation, uma organização sem fins lucrativos sediada na Arábia Saudita que o Departamento do Tesouro dos EUA designou como uma organização terrorista. Osama bin Laden, o cérebro por trás dos ataques de 11 de setembro, referiu-se à lista manuscrita dos 20 nomes como a "Corrente Dourada". (Ryle et al., 2015, p.14)

A atuação de contrabandistas de diamantes se refere a outro grupo de clientes e inclui a descrição dos procedimentos ou esclarece sobre a dinâmica do comércio de pedras preciosas, muitas vezes, com evidências de crimes, como o envolvimento com "diamantes de sangue": 
Diamantes de sangue, ou diamantes de conflito, são termos usados para gemas extraídas em zonas de guerra que depois são vendidas para financiar mais guerras. Diamantes extraídos durante as recentes guerras civis em Angola, Costa do Marfim, Serra Leoa e outras nações receberam o rótulo. "Os diamantes têm uma longa história de estarem ligados a conflitos e violência", disse Michael Gibb, do grupo internacional de direitos humanos Global Witness. "A facilidade com que os diamantes podem ser convertidos em ferramentas de guerra, quando não fornecidos de forma responsável, é surpreendente." (Ryle et al., 2015, p.13)

As redes e associações entre criminosos referem-se aos relacionamentos, por vezes, não formais, estabelecidos entre agentes criminosos como patrocínios, compra e venda, investimentos, sociedades e intercâmbio de informações privilegiadas, cujo intuito é realizar operações lucrativas e ilícitas, valendo-se do conluio com o sistema financeiro:

Ele teria começado seu grande comércio de armas por diamantes
em guerras civis africanas durante os anos 1990, em violação aos
embargos da ONU. Um relatório do Conselho de Segurança de 2001
encontrou "fontes muito confiáveis" que relataram um acordo secreto
que, em troca de um acordo dando a Gertler o monopólio dos direitos
de diamante no Congo, o israelense "concordou em organizar, através
de suas conexões com oficiais militares israelenses de alta patente,
a entrega de quantidades não divulgadas de armas, bem como
treinamento para as forças armadas congolesas." (Chittum, 2015, p.5)

A cumplicidade do sistema financeiro com esses atores remete a formas de acumulação de capital violentas, que ignoram e desprezam a vida, particularmente, daquelas distantes da metrópole, em uma versão contemporânea da dominação colonial (Coronado, 2008; Watson, 2016), fato que aproxima seus agentes a postura de necrocapitalistas (Banerjee, 2008a).

Desinformação contém um conjunto de posturas e declarações dos acusados e indiciados em virtude do seu envolvimento, ou suposto envolvimento, em atividades ilícitas que deixam de informar ou, ainda, informam erroneamente. Os padrões de desinformação foram associados à cumplicidade pelo ardil subentendido nas estratégias manifestadas, incluindo desde a simples negação, passando pelas alegações de que padrões antigos permitiam essas falhas, até esclarecimentos de que novas regras foram implementadas. As declarações permitiram constatar padrões ritualizados dos bancos suíços como culpabilização de agentes do passado, com alegações ao público de arrependimento, tolerância e conivência com as contravenções conhecidas de seus clientes (Carlin \& Lokanan, 2018).

Negação de potencial contravenção refere-se ao conjunto dos posicionamentos que contêm declarações de inocência por parte dos indivíduos e instituições indiciados nas investigações ou citados em reportagens e vazamentos de dados. De forma geral, esses são os pronunciamentos padrões aos jornalistas, bem como em processos, em tribunais ou para outras fontes de acusação:

Outros negaram irregularidades ou não ofereceram explicações para suas retiradas quando contatados pelo The Guardian. Na ausência de qualquer explicação, não é possível avaliar se as retiradas foram para fins legítimos. Arlette Ricci, a herdeira do perfume Nina Ricci, tinha o equivalente a $£ 15$ milhões em contas suíças. O banco forneceu-lhe 10 pacotes de $€ 7.500$ cada ao longo de 2005, totalizando cerca de $€$ 60.000. Ela nega todas as transgressões. (Leigh et al., 2015c, p.2) 
Alegação de que essas falhas não ocorrem mais foram encontradas em declarações, muitas vezes, expressando arrependimento dos indiciados e reconhecendo que estruturas, condições ou procedimentos não adequados e falhos, existiam em seus negócios em determinado momento do passado, mas foram revisados ou substituídos por outros mais adequados ou, ainda, de padrão superior:

Reconhecemos e somos responsáveis por falhas passadas de conformidade e controle. Demos passos significativos nos últimos anos para implementar reformas e sair de clientes que não atendiam aos novos e rigorosos padrões do HSBC. O HSBC Private Bank Swiss reduziu sua base de clientes em quase $70 \%$ desde 2007. (Leigh, et al., 2015a, p.1)

O apoio às investigações e reformas, foi encontrado em declarações dos indiciados, assim como apoio às reformas legais e regulatórias nos setores bancário e fiscal, e declarações de autopromoção, como divulgação de investigações e reformas internas em função das denúncias. Não se investigaram, nesses casos, a veracidade e a sinceridade das declarações, mas, a postura dos indiciados:

\begin{abstract}
O HSBC disse em seu comunicado ao IClJ que estava "totalmente comprometido com a troca de informações com as autoridades relevantes" e estava "ativamente buscando medidas que garantam que os clientes sejam transparentes, mesmo antes de uma exigência legal ou regulatória para fazê-lo. Também estamos cooperando com as autoridades relevantes que investigam essas questões." (Ryle et al., 2015b, p.10)
\end{abstract}

A dissimulação refere-se a posicionamentos dos citados ou acusados, utilizando técnicas de comunicação para induzir ao erro ou passar uma imagem falsa da realidade. Inclui-se também a mudança do foco da questão mediante supressão ou ocultação de informações, minimização da importância ou modificação do sentido, inferências feitas pelos próprios jornalistas, direta ou indiretamente:

\begin{abstract}
Em uma entrevista com a al-Arabiya poucos dias antes da queda de Mubarak, Rachid rejeitou alegações sobre sua riqueza como "mentiras claras", acrescentando que ele havia lutado para "combater a corrupção contra personagens proeminentes e poderíamos ter feito muito mais". Rachid disse que ele estava "pronto para interrogatório" pelas autoridades, mas não retornou ao Egito após a renúncia de Mubarak. (Leigh et al., 2015f, p.2)
\end{abstract}

Admissão de culpa, mas não de dolo refere-se a um conjunto de posicionamentos dos acusados em que há, explicitamente, ou não, admissão da conduta voluntária na realização do ato, mas sem a intenção de causar o resultado danoso, havendo alegações de negligência, imprudência ou imperícia, que acabaram levando ao resultado "inesperado":

Em sua curta expressão de "arrependimento" após a desgraça do HSBC no México e na Colômbia, Lorde Green falou timidamente em 2012 sobre "falhas de implementação", mas nunca se sujeitou a questionar o motivo pelo qual elas aconteceram. (Pratley, 2015, p.3)

Silêncio diante de indícios e acusações refere-se à opção de indivíduos e instituições, financeira ou governamentais, citados nas investigações ou reportagens de não comentarem, quando questionados pela mídia, sobre qualquer fato, indício ou investigações em que seu nome seja citado, 
tratando-se, na maioria dos casos, de repostas padrões. Para eventos relacionados com instituições lotadas em jurisdições onde há legislação de sigilo bancário, esse é, usualmente, o argumento utilizado, como: "O HSBC diz que não comentará muitas das alegações específicas por causa de investigações criminais em andamento e por causa das leis suíças de sigilo bancário" (Leigh et al., 2015b, p.3).

Nesse conjunto de posicionamentos dos acusados há, explicitamente ou não, a admissão da conduta voluntária na realização do ato, mas sem a intenção de causar o resultado danoso, havendo alegações de negligência, imprudência ou imperícia, que acabaram levando ao resultado "inesperado". Os posicionamentos de "dissimulação" e "negação de potencial contravenção" são as táticas de racionalização da corrupção utilizadas pelo banco como forma de legitimar seus atos, o que pode levar à normalização e perpetuação da corrupção (Anand, Ashforth, \& Joshi, 2004; Ashfort \& Anand, 2003; De Klerk, 2017; Freitas \& Medeiros, 2018). Existe uma lacuna entre a prática organizacional interna, direcionada para resultado e lucro, e os discursos corporativos para o público externo (Dion, 2013; Sikka, 2010). No material analisado, indivíduos ou corporações que atuam globalmente fogem da responsabilidade quando se associam a contraventores, obtendo benefício econômico à custa dos direitos das comunidades fraudadas ou, mais além, dos direitos humanos, por reconhecerem a improbabilidade de serem responsabilizados em um tribunal (Banerjee, 2008a).

\section{Tema final 2: impunidade}

Diferentes formas de poder, seja institucional, material ou discursivo, operam na atual economia política regida pela globalização, permitindo a articulação de formas de acumulação de capital que se utilizam, ou resultam, de violência e morte. Nesse contexto, corporações multinacionais se eximem da responsabilidade ao se associarem a esses regimes repressivos (Banerjee, 2008a), ativa ou passivamente, como no caso das instituições financeiras que permitem a lavagem de dinheiro do tráfico ou da corrupção por meio de complexas transações, envolvendo remessas de dinheiro sem fiscalização, contas em paraísos fiscais e empresas e fundos offshore envoltos em camadas de sigilo.

Essa "área cinzenta" da cumplicidade corporativa, na qual a extração de benefícios econômicos se origina da violação de direitos humanos ou da penalização do bem-estar social de todo um país, é de difícil comprovação perante um Tribunal de Justiça. Assim, torna-se um padrão observar que "as corporações transnacionais parecem operar com impunidade [...] no que diz respeito ao domínio do direito internacional” (Banerjee, 2008a, p. 1557).

Particularmente, no setor financeiro, quando são grandes o suficiente para serem classificadas como "sistemicamente importantes", essas corporações usufruem da impunidade de uma forma peculiar em virtude da ausência de compensação entre as sanções passíveis legalmente e a dimensão dos ilícitos e seus efeitos para a sociedade (Hardouin, 2017; Sikka, 2008). A responsabilização criminal dos indivíduos envolvidos e, nesses casos, inclusive dos executivos seniores, vem sendo discutida como provavelmente 
uma das ações mais eficientes na busca desse equilíbrio entre penalizações e crimes (Global Witness, 2015; Hardouin, 2017).

A impunidade compreende a associação de seis temas intermediários: justiça autorizada, negligência, imperícia, ligações perigosas, indiferença e disrupção, revelando outra face dos esquemas de corrupção transnacional sob o ponto de vista do sistema financeiro, enquanto a cumplicidade refere-se à associação desses atores em conluio com os contraventores.

A justiça autorizada constitui um conjunto de fatos e interesses para garantir alguma eficiência da justiça com o estabelecimento de investigações, processos, execuções, prisões e outros aparatos jurídicos. A corrupção se converteu em uma barreira à implantação de estratégias econômicas transnacionais pelos riscos econômicos e incertezas que se associam aos investimentos e, portanto, não é coincidência que a luta contra a corrupção mobilize os mesmos defensores da globalização econômica (Bratsis, 2014; Williams \& Beare, 1999). Entretanto, essa questão ainda tem poucos resultados concretos e, por maiores que sejam seus custos humanos e sociais, os incentivos distorcidos promovem, ao invés de coibir, a participação do sistema financeiro nas complexas redes estabelecidas para ocultar a corrupção.

A categoria atuação esperada da justiça se refere a decisões e ações movidas pelos órgãos de justiça, envolvendo a condução de investigações ou, quando conclusivas, o processamento e a execução de instituições e seus agentes, quando os indícios de fraude ou crime se comprovam, não necessariamente se referindo ao caso em análise, mas a outras conduções associadas aos indivíduos ou instituições citadas, conforme o trecho a seguir mostra:

O chanceler pediu às agências de fiscalização do Reino Unido que investiguem se os grupos bancários britânicos HSBC e Standard Chartered estão ligados ao inquérito de corrupção da África do Sul sobre supostos laços entre a rica família Gupta e o presidente Jacob Zuma. De acordo com cartas vistas pelo The Guardian, Philip Hammond passou as preocupações levantadas pelo ex-ministro do Trabalho, Peter Hain, para o Serious Fraud Office (SFO), a National Crime Agency (NCA) e a Financial Conduct Authority (FCA). (Davies, 2017, p.1)

A indignação com práticas financeiras ilícitas é uma categoria que reúne declarações de indignação e intolerância diante de condutas consideradas fraudulentas, criminosas ou antiéticas de instituições financeiras (bancos, escritórios de advocacia, imobiliárias, outros) e seus clientes, normalmente referindo-se a um caso específico ou ao posicionamento da justiça. Além disso, tem um caráter de discurso, sendo normalmente pronunciado em assembleias e julgamentos, utilizando, por vezes, recursos como ironia e perguntas retóricas:

Andrea Leadsom, Ministra do Tesouro, disse que as pessoas que erraram "não estarão de volta em uma sala de negociações com um grande salário" e que "tudo o que pode ser feito para punir esse tipo de comportamento" será feito. Ela disse ao programa Today da BBC Radio 4: "É completamente repugnante. Eu acho que os contribuintes ficarão horrorizados ... Eu não sei se a corrupção é uma palavra forte o suficiente para isso." (Treanor, 2014, p.1) 
A colaboração entre jurisdições e instituições refere-se à articulação de distintas jurisdições ou instituições (políticas, jurídicas, comerciais ou sociais) com troca de informações e documentos, no intuito de auxiliar na prevenção e no combate às fraudes e crimes, apesar de não necessariamente serem efetivas:

\begin{abstract}
Os arquivos secretos obtidos pelo IClJ - cobrindo contas até 2007 associadas a mais de 100.000 pessoas físicas e jurídicas de mais de 200 nações - são uma versão das que o governo francês obteve e compartilhou com outros governos em 2010, levando a processos ou acordos com indivíduos por evasão fiscal em vários países. As nações cujas autoridades fiscais receberam os arquivos franceses incluem os EUA, Espanha, Itália, Grécia, Alemanha, Grã-Bretanha, Irlanda, Índia, Bélgica e Argentina. (Ryle et al., 2015, p.2)
\end{abstract}

Interesses políticos interferem em procedimentos legais ou processuais, consolidando um conjunto de situações que demonstram interesses políticos que se estabelecem para interferir em acordos legais, corpus de leis ou procedimentos jurídicos que tenham como intuito coibir crimes financeiros. Por vezes, os interesses favorecem, mas existem também exemplos de que o sistema se fragilizou:

No início deste ano, como resultado do acordo que levantou as
sanções econômicas contra o Irã em troca das partes chave de seu
programa nuclear, os Estados Unidos removeram a Petropars e outras
companhias petrolíferas controladas pelo Irã da lista negra da OFAC.
(Fitzgibbon \& Hamilton, 2016, p.6)

Acusação criminal de pessoa física associada à instituição financeira refere-se aos indiciamentos ou acusações criminais de pessoas físicas associadas à instituição financeira envolvida no delito em causa, seja banco, escritório de advocacia, imobiliárias ou outros. Nessas situações, o indiciado pode ser diretamente responsável pela execução, coordenação ou aprovação da ação em si e as penas incluem privação de liberdade, devolução de valores envolvidos e/ou outras multas pecuniárias. Em muitas situações, a instituição também é responsabilizada, mas, na maioria dos casos, não criminalmente. Essa foi a categoria menos representativa do tema, coerente com as críticas de que existe impunidade no setor: "Eles são os primeiros a serem acusados em conexão com a investigação de longa data do governo dos EUA sobre o suposto rigging [manipulação de taxas] por banqueiros em um mercado de câmbio de USD 5,3 trilhões (£ 4 trilhões) ao dia" (Neate \& Treanor, 2016, p.1).

O tema negligência, aqui é considerado como falta de cuidado encontrada em um conjunto de situações e circunstâncias que acabam por favorecer a corrupção dos agentes financeiros em virtude da ausência de medidas coercitivas suficientes. Em algumas categorias, existe a ação das autoridades, mas de uma forma branda quando comparada com o dano real ou potencial que se pretende reparar; já em outras, existe o conhecimento das autoridades sobre circunstâncias que, potencialmente, incentivam a formação de carteis, lavagem de dinheiro, evasão fiscal e corrupção, tais como sigilo e ambientes regulatórios deficientes. Entretanto, para essas circunstâncias não são definidas medidas regulatórias à altura (Sikka, 2008), o que, muitas vezes, demonstra falta de interesse político das autoridades e governantes (Christensen, 2011). 
Acordos DPA e similares são aqueles que encerram investigações com a suspensão condicional, ou total, do processo criminal, implicando em outras penalizações pelo delito. Em alguns países, como EUA e UK, o modelo mais conhecido desse acordo é o Deferred Prossecution Agreement (DPA - Acordo de Acusação Diferida), podendo possuir outros nomes em países diferentes. De forma geral, em função de questões como a natureza do delito, colaboração da empresa na condução das investigações e seu compromisso de não recorrência, suspende-se temporariamente a acusação criminal e aplica-se multa pecuniária, com recuperação de valores quando pertinente e instituição de monitores internos independentes pelo prazo de vigência do acordo. Após esse período, se atendidos os critérios estabelecidos no acordo, o processo criminal é arquivado pelas autoridades, o que é considerado por alguns críticos como um processo excessivamente tolerante e, por isso, negligente, visto que as dimensões limitadas da sanção não inibem a disposição da instituição ao risco.

\begin{abstract}
O HSBC foi condenado a pagar um valor recorde de 40 milhões de francos suíços (£28 milhões) e recebeu uma advertência final das autoridades de Genebra por "deficiências organizacionais" que permitiram a lavagem de dinheiro na subsidiária suíça do banco. O acordo significa que a Suíça não processará o HSBC ou publicará as conclusões de sua investigação sobre a suposta lavagem de dinheiro agravada. Mas o promotor-chefe de Genebra, Olivier Jornot, advertiu que o banco está em aviso, dizendo: "Esta é uma desculpa que só será aplicada uma vez." (Garside, 2015, p.1)
\end{abstract}

A competição do mercado financeiro incitando fraudes é uma categoria que se refere às declarações e opiniões encontradas no corpus que associam, explicitamente, a dinâmica do mercado financeiro capitalista, racional, competitivo e global com a ocorrência de crimes e fraudes, uma vez que burlar ou negligenciar regras específicas criam formas de aumentar a lucratividade institucional e/ou pessoal, seja: ampliando a carteira de clientes pelo tratamento "diferenciado"; otimizando impostos; manipulando taxas de câmbio; e estimulando bônus anuais de funcionários e executivos a taxas de performance desafiadoras que não consideram compliance como parâmetro.

\begin{abstract}
"No HSBC, seus executivos ainda não entendem", disse Dennis Lormel, ex-chefe da unidade de crimes financeiros do FBI, em uma entrevista. "Eles estão mais fora do controle do que no controle." A cultura do banco não mudará, acrescentou, "até que o lado do negócio tenha sua remuneração vinculada ao desempenho de compliance." (Smith, \& Babcock, 2015, p.3).
\end{abstract}

Segredo financeiro favorece operações ilícitas refere-se às declarações e citações que enfatizam a questão de que estruturas legais, das jurisdições que protegem o segredo financeiro, acabam por favorecer e incentivar a ocorrência de operações ilícitas do ponto de vista legal ou moral, neste último, no caso de elisões fiscais indevidas. As leis que estabelecem o segredo de jurisdições offshore, ou onshore, como alguns exemplos norte-americanos, são estabelecidas e reguladas pelas autoridades locais, mas ainda são aceitas globalmente pelas maiores potências mundiais apesar de todas as críticas. É por isso que há a associação com o tema negligência. 
As empresas britânicas registadas desempenharam um papel proeminente nesta extensa rede de lavagem de dinheiro. Os verdadeiros donos da maioria das firmas usadas no esquema permanecem secretos, [...], devido ao anonimato proporcionado pelas polêmicas leis offshore (Harding et al., 2017, p.1).

Regimes especiais de regularização cambial e tributária, ou suas variações legais, dizem respeito aos arranjos que permitem a regularização de recursos, bens ou direitos de origem lícita, não declarados ou declarados incorretamente, remetidos, mantidos no exterior ou repatriados por residentes em determinada jurisdição para efeito fiscal. Com esse regime, o objetivo de arrecadação pelos governos é atingido mais rapidamente, pois não são necessárias investigações e acusações, entretanto a questão de justiça é negligenciada, pois as multas aplicadas são menores e não há outros tipos de sanções.

Em dezembro de 2014, a ATO [Australian Tax Office] encerrou um prazo para conceder anistias no "Projeto DO IT", que permitia que pessoas que pudessem ter ativos offshore não declarados se apresentassem (Farrel et al., 2015, p.1-2).

Não acusação criminal de pessoa física refere-se ao não indiciamento criminal de qualquer pessoa(s) física(s) associada(s) à instituição financeira responsabilizada legalmente pelo delito, ficando, nesses casos, somente a pessoa jurídica como responsável e passível de multa ou sanções (banco, escritório de advocacia, imobiliárias, outros). Essa é uma questão bastante controversa, pois muitos especialistas consideram que seria o caminho mais efetivo para se coibir a criminalidade no setor financeiro, mostrando-se como uma sanção compatível com os incentivos a riscos oferecidos pelo setor.

\begin{abstract}
John Coffee, professor de direito na Columbia Law School em Nova York, disse que a multa era consistente com a forma como os reguladores norte-americanos vêm tratando infrações bancárias nos últimos anos. "Atualmente, eles raramente processam indivíduos de maneira significativa quando a entidade tem um acordo. Isso é, em grande parte, em função das limitações de recursos, mas também da aversão ao risco e da disposição de tomar o curso de menor resistência", esclareceu (Rushe \& Treanor, 2012, p.3)
\end{abstract}

A negligência foi identificada nos posicionamentos das autoridades globais e locais, que representam pouca ou nenhuma preocupação com a justiça. Nas categorias identificadas por essa temática, existe a compreensão de que as particularidades das distintas estruturas jurídico-legais, muitas vezes, incentivam, como nos casos do segredo financeiro e dos incentivos para alocação de capital ou planejamento tributário, a criminalidade e a fraude das grandes corporações e fortunas. Quando se trata do capital global, as decisões das autoridades podem ser reduzidas a uma questão de arrecadação, e não de coerção, que seria o comportamento esperado da justiça. A presença do discurso colonial é caracterizada não pela homogeneidade, mas pela sua ambivalência e contradição (Prasad, 2003), praticando uma medida de justiça para o colonizado, e outra, muito mais complacente, para os colonizadores.

Imperícia se refere à falta de capacidade, sendo o termo utilizado para o tema que agrupa categorias nas quais há incapacidades ou dificuldades dos aparatos jurídico-legais, nacionais e internacionais, de aturarem para coibir a criminalidade transnacional contida no atual sistema financeiro globalizado. 
Apesar da pressão internacional para adequação das legislações locais de coerção à corrupção transnacional exercida por convenções, como da OCDE (OECD, 2017) e das Nações Unidas (United Nations Office on Drugs and Crime, 2004), "obstáculos estruturais, legais, evidenciais, processuais e financeiros" (Lord, 2014, p. 116) persistem, como demonstrado nessas situações.

A morosidade de agentes governamentais é uma categoria que se refere às situações nas quais interesses, nem sempre declarados, desfavorecem a agilidade para reformas legais e/ou investigações, acusações ou execuções por crimes e fraudes financeiras. Os interesses podem ser relacionados, por exemplo, a envolvimento pessoal, de pessoas próximas, de políticos ou de elites e de grandes empresas do país. Alegações de interesse financeiros nacionais, como no caso das jurisdições offshore, também são consideradas nessa categoria. Difere-se da categoria "falta de aparato jurídico legal" por não se limitar a questões estruturais vigentes, mas à morosidade intencional em executar algo previsto:

\begin{abstract}
A Grécia recebeu os nomes em 2010, mas nada aconteceu até outubro de 2012, quando uma revista grega, Hot Doc, publicou os nomes e observou a falta de uma investigação sobre se os gregos ricos estavam fugindo dos impostos enquanto o país passava por medidas de austeridade, incluindo cortes salariais e aumento de impostos para os contribuintes. [...] dois ex-chefes da polícia financeira testemunharam que nem o ex-ministro das finanças Giorgos Papakonstantinou nem seu sucessor ordenaram uma investigação sobre a lista. Papakonstantinou disse que havia sido perdida. Quando a lista finalmente apareceu, faltavam os nomes de três parentes de Papakonstantinou (Ryle et al., 2015b, p.11)
\end{abstract}

Falta de aparato jurídico legal para atuação efetiva refere-se às situações, fatos ou alegações de especialistas sobre dificuldade estruturais para que a justiça possa atuar de forma efetiva. Envolve desde questões como restrições legais locais ou internacionais, até a falta de pessoal, estrutura e/ ou orçamento para investigações mais complexas e rápidas. Essa categoria é relevante considerando que o "mercado" para ilícitos é dinâmico e possui recursos suficientes para se "adaptar", com velocidade, a quaisquer novas mudanças ou sanções.

Explicando a decisão de não levar o HSBC ao tribunal, Jornot disse que a lei suíça exige um alto padrão de prova. A lavagem de dinheiro tem de ser demonstrada como realizada deliberadamente, não por acaso, e o dinheiro teve que ser comprovadamente obtido de atos criminosos, e não simplesmente depositado por um criminoso conhecido. Para multar o banco, os promotores também precisariam demonstrar que falhas organizacionais fizeram com que o dinheiro fosse lavado. Além disso, muitas das revelações nos dados de Falciani, que deram uma imagem detalhada dos eventos no banco entre 2005 e 2007, diziam respeito a contas antigas ou pessoas que não eram mais clientes do banco. (Garside, 2015, p.3)

Falta de colaboração entre jurisdições e instituições, trata de situações nas quais, por interesses nem sempre declarados, não há colaboração entre jurisdições ou instituições (políticas ou jurídicas), o que dificulta ou inviabiliza a troca de informações e documentos que poderiam auxiliar na prevenção e no combate aos crimes financeiros: 
Falando ao The Guardian, o chefe da unidade de lavagem de dinheiro da NCA, David Little, disse que a quantidade de dinheiro russo que chega agora ao Reino Unido é uma preocupação porque "não sabemos de onde vem". "Não temos cooperação suficiente [do lado russo] para estabelecer isso. Eles não vão nos dizer se isso vem de lucro do crime. "(Hopkins, Harding, \& Mason, 2017, p.2)

O tema imperícia aponta para a incapacidade condicionada às autoridades e à justiça em virtude de circunstâncias estruturais mantidas ou por interesses daqueles que detêm o poder, colaborando para a impunidade daqueles que se servem dessas lacunas do sistema. Observamos que fragilidades no aparato jurídico-legal dificultam o combate à criminalidade e à fraude das grandes corporações e fortunas. Apesar dos esforços confirmados em convenções multilaterais de combate à corrupção, ainda existe um longo caminho para conformação da sua realidade prática de forma que, realmente, consigam se posicionar contra a corrupção do sistema. As situações contidas nessa temática revelam características do discurso colonial formado por fissura e ambivalência (Prasad, 2003), pois ao mesmo tempo em que se conclama o combate à criminalidade, não se é capaz de articular mecanismos para que realmente se efetivem essas ações.

Ligações perigosas remetem a um conjunto de situações que sugerem uma proximidade "arriscada" entre agentes do setor público e privado. A relação entre os interesses privados e a formulação de políticas públicas é complexa eantiga, e influências indevidas não são raras (Sikka \& Lehman, 2015; Sikka, 2008). Políticas inconvenientes, do ponto de vista das corporações, acabam sendo diluídas por meio de ações como lobbying, financiamento de partidos políticos ou da mídia (Sikka, 2008; Sikka \& Lehman, 2015). Algumas das relações observadas demonstram um risco potencial nessa proximidade, do ponto de vista da integridade das instituições públicas, e essa é a essência expressa no tema ao descrever, por exemplo, doações a partidos políticos por magnatas que usufruem de contas offshore para "planejamento tributário" ou, ainda, executivos de empresas envolvidas em corrupção que assumem cargos públicos proeminentes.

Proximidade de funcionários públicos e instituições financeiras se refere às descrições que evidenciam relacionamentos próximos, comerciais ou não, entre funcionários públicos (legislativo, executivo ou judiciário) e agentes das redes financeiras (bancos, escritórios de advocacia, imobiliárias, outros). Como exemplo, podem ser citados: ex-políticos como fundadores ou executivos dessas instituições; parentes de políticos com cargos em instituições financeiras; políticos e parentes com contas offshore (declaradas ou não) estruturadas por meio de agentes questionados em investigações, como o HSBC, por exemplo; políticos, familiares ou assessores com investimentos, utilizando complexas estruturas offshore; funcionários públicos de alto escalão que passam a trabalhar para instituições financeiras, entre outras possibilidades.

Enquanto presidente do HSBC, Green, [...], mantinha relações comerciais com figuras importantes do regime egípcio. Em 1998, ele copresidiu o Conselho Empresarial Britânico do Egito, um grupo de alto nível que reportou aos então primeiros-ministros britânico e egípcio, Tony Blair e Kamal Ganzouri. O ex-ministro de investimentos do Egito, Mahmoud Mohieldin, responsável pelas privatizações por seis anos até 2010, foi diretor do HSBC Egito antes de ingressar no governo, assim como Rachid Mohamed Rachid, ministro do comércio (Mathiason \& Barr, 2011, p.2) 
Doações políticas referem-se às doações propriamente ditas, bem como a outras formas de "contribuição", como lobbying e empréstimos, direcionadas a políticos, partidos ou fundações, sendo realizadas por aqueles citados nos vazamentos ou pelas instituições financeiras investigadas nos mesmos escândalos. As doações não indicam, necessariamente, que houve uma intenção ilícita envolvida, entretanto, sinalizam uma dificuldade de se obter comprometimento político suficiente para fortalecer o aparato jurídico- legal e combater as brechas do sistema financeiro, quando algumas delas são utilizadas pela mesma elite que financia a política:

\begin{abstract}
Os arquivos mostram Caring, um importante doador na política britânica, transferindo USD 1 milhão para a Clinton Foundation, uma organização sem fins lucrativos criada pelo ex-presidente dos EUA Clinton com a missão declarada de "fortalecer a capacidade das pessoas nos Estados Unidos e em todo o mundo" para enfrentar os desafios da interdependência global". A doação para a Fundação Clinton foi solicitada em dezembro de 2005. (Ryle et al., 2015, p.8)
\end{abstract}

Sucesso político de ex-executivos de empresas indiciadas refere-se aos casos em que ex-executivos de empresas envolvidas em investigações, ou condenadas, assumiram posições políticas de prestígio nos seus respectivos países. Apesar de não indicarem, necessariamente, algo ilícito, ao menos na versão pública dos fatos, se associam fortemente com o tema da impunidade, uma vez que as questões envolvendo o histórico da fraude são totalmente desconsideradas para a indicação ao cargo público de prestígio, como: "Lorde Stephen Green, chefe do HSBC durante o período coberto pelos registros, tornou-se Ministro do Comércio no governo Cameron, na Grã-Bretanha, cargo que ocupou até 2013" (Hamilton, 2015, p.10).

Decisões controversas referem-se a decisões ou vereditos promulgados por determinados atores governamentais que são fortemente questionadas pelos pares e/ou pelo público em geral em função dos interesses envolvidos, os quais são considerados não legítimos. Os fatos em si podem ter sido considerados como parte de outra categoria, mas questões que compõem essa categoria, especificamente, têm como padrão haver uma crítica ou controvérsia pública, demonstrando uma decisão não unânime em que uma das partes se posiciona pela impunidade:

Em 18 de fevereiro, Jornot ordenou uma busca aos escritórios do HSBC em Genebra, um dia depois o promotor federal da Suíça, Michael Lauber, ter dito à imprensa que não havia pedido de inquérito sobre irregularidades no banco. Lauber argumentou que não era apropriado que o estado lançasse uma investigação sobre o HSBC com base em informações roubadas. (Garside, 2015b, p.1-2)

As categorias identificadas no tema ligações perigosas foram interpretadas como situações que favorecem ou foram favorecidas pela impunidade em virtude de aspectos que podem ser interpretados como corrupção, mas que são obscurecidos a ponto de as relações sociais parecerem consequência de forças invisíveis ou naturais (Silbey, 1997). Se, no período do império, a "força da espada" era mais visível nas relações entre autoridades e corporações, na era pós-colonial essa violência assume formas mais discretas (Banerjee, 2008a), mas que também refletem o conluio das elites políticas para garantir a impunidade daqueles que mantêm ativas as engrenagens do comércio e da globalização. 
A temática da indiferença em relação às vítimas foi outro padrão encontrado no material empírico. Distinguem-se nele duas categorias de indivíduos, segundo a dimensão de subordinação, que se encontram na sociedade: os "subalternos", os quais não têm direito de expressão em virtude da miséria ou violência a que estão submetidos (Spivak, 1988); e a que foi chamada "sociedade comum" que, mesmo penalizada ou não atendida, ainda tem recursos que lhe permitem algum nível de expressão e manifestação. Uma terceira categoria, não associada a indivíduos, pôde ser identificada a partir do contexto colonial da globalização, que é a fragilidade institucional dos países periféricos. Apesar de ser uma consequência (ou como denominamos, vítima) da colonialidade, muitas vezes essa fragilidade é transformada em causa no discurso hegemônico e utilizada como justificativas para as diferenças de crescimento e riqueza entre as nações, além de ser associada a argumentos como inferioridade cultural e/ou ética das regiões mais miseráveis (Bratsis, 2014), confirmando, portanto, a continuidade do projeto colonial (Watson, 2016).

A penalização dos subalternos está associada aos eventos e situações nas quais o custo da fraude, ou crime financeiro, recai sobre os grupos menos favorecidos da sociedade, ou seja, aqueles que não têm voz e não terão outra alternativa a não ser arcar com o sofrimento decorrente. São, por exemplo, os casos de vítimas de traficantes de armas, drogas e diamantes; comércios que não existiriam se não houvesse um sistema financeiro que aceitasse o ilícito; a corrupção e o segredo que normalmente envolvem essas transações:

Foi uma cena de incrível carnificina. Em julho de 2003, um grupo rebelde recentemente armado, os Liberianos Unidos pela Reconciliação e pela Democracia, retomou o cerco de dois meses à capital, Monróvia, lutando para tirar o controle do país do presidente Charles Taylor. As crianças-soldado estavam lutando em ambos os lados, em uma área cheia de civis. Na batalha conhecida localmente como "Terceira Guerra Mundial", os jovens soldados que lutavam pelos rebeldes estavam armados com o que o The Economist chamou de "novos brinquedos reluzentes", com os quais não tinham experiência. Os combates deixaram centenas de civis mortos e outros 2.000 feridos (Fitzgibbonl \& Hamilton, 2015, p.1).

A penalização da sociedade comum descreve eventos ou situações nas quais o custo da fraude ou crime financeiro recai sobre a sociedade como um todo. São os casos, por exemplo, de evasão e elisão fiscal de grandes fortunas, normalmente associadas às elites, recaindo os custos sobre aqueles que não têm acesso a essas alternativas de "otimização tributária". Logo, isso os leva a arcar com a maior parte dos tributos para manutenção do bem-estar social no país: "Quatro famílias de norte-americanos mortos por cartéis de drogas mexicanos estão processando a gigante do setor bancário britânico HSBC por, supostamente, ter contribuído para sua morte, permitindo que as facções lavassem bilhões de dólares" (Dart, 2016, p.1).

A fragilidade institucional de países periféricos refere-se a fatos e eventos que expõem a fragilidade institucional dos países não centrais, seja pela debilidade das leis, seja pela dificuldade do seu corpo jurídico de colocá-las em prática ou, ainda, em virtude das forças políticas que se articulam para que medidas mais severas contra fraudes e crimes financeiros não sejam efetivadas nessas localidades: "Angola, o estado ocidental Africano, rico 
em petróleo, é descrito pelo Senado como tendo 'controles fracos contra a lavagem de dinheiro e um sistema bancário intensivo em dinheiro'. Seu banco central, o Banco Nacional de Angola, detinha cerca de USD 1,25 bilhão em ativos em dezembro de 2004" (Mathiason, 2010, p.1).

Assim, o tema indiferença representa as vítimas desse processo. Tomamos emprestado o termo "subalterno" para nos referir às vítimas que estão fora da estrutura hegemônica social, política e geográfica (Spivak, 1988), como as vítimas dos conflitos armados na África, dominada por traficantes de armas e diamantes de sangue, ou na América Latina, pelo tráfico de drogas. Também em posição de vítima, mas em uma dimensão menos anônima, está a sociedade comum, que pode ser considerada, ao menos geograficamente, com algumas liberdades dentro da estrutura, como os cidadãos europeus ou norte-americanos, por exemplo. Quando nos referimos à fragilidade institucional de países periféricos, buscamos suporte no conceito de necrocapitalismo (Banerjee, 2008a), segundo o qual corporações transnacionais contribuem para a desapropriação e subjugação da vida, valendo-se não apenas da violência física, mas daquela que se apresenta na cooptação das elites locais para exploração por meio da comercialização dos seus próprios estados e cidadãos.

O último tema consolidado denomina-se disrupção, e reconhece um ponto de resistência ao padrão da impunidade, uma ruptura, uma interrupção do curso normal de um processo. Sendo assim, é nessa perspectiva que se destacam atores não convencionais nas discussões sobre governança corporativa, que são, muitas vezes, considerados não importantes, mas compõem as fontes mais representativas na detecção e delação das fraudes: a mídia, os funcionários e os agentes reguladores não financeiros.

Jornalismo investigativo se refere aos jornalistas independentes que têm se contraposto ao sistema e, muitas vezes, com a colaboração de delatores, tem divulgado dados e reportagens que permitem ou, às vezes, pressionam as autoridades no sentido de coibir a criminalidade:

\footnotetext{
Os registros vazados - que foram revisados por uma equipe de mais de 370 jornalistas de 76 países - vêm de um escritório de advocacia pouco conhecido, mas poderoso, com sede no Panamá, o Mossack Fonseca, que possui filiais em Hong Kong, Miami, Zurique e mais de 35 outros lugares ao redor do globo. A empresa é uma das maiores criadoras mundiais de empresas de fachada, estruturas corporativas que podem ser usadas para ocultar a propriedade de ativos. Os arquivos internos vazados do escritório de advocacia contêm informações sobre 214.488 entidades offshore conectadas a pessoas em mais de 200 países e territórios. O IClJ divulgará a lista completa de empresas e pessoas ligadas a elas no início de maio. Os dados incluem e-mails, planilhas financeiras, passaportes e registros corporativos, revelando os proprietários secretos de contas bancárias e empresas em 21 jurisdições offshore, de Nevada a Cingapura, às Ilhas Virgens Britânicas. (Smith \& Babcock, 2015, p.2-3)
}

Insegurança dos delatores se refere às situações em que delatores, voluntários ou circunstanciais, ficam expostos por terem revelado informações secretas, envolvendo tanto a contradição das fontes que ele(s) delataram, podendo estas serem, muitas vezes, instituições poderosas que irão negar ou contradizer a versão do delito, quanto à insegurança jurídica, uma vez que as informações contidas na delação podem ter sido roubadas ou serem 
sigilosas em algumas jurisdições. Logo, isso gera a exposição a processos legais, incluindo a insegurança física e levando à necessidade de guarda-costas, alteração de endereço, extradição e outros:

\begin{abstract}
A Omega [empresa] deixou a Bélgica depois que David Renous, um denunciante que trabalhou para Omega comercializando com diamantes de Angola e da República Democrática do Congo e que afirma que o $\mathrm{FBI}$ impediu duas tentativas contra sua vida, informou às autoridades, em 2006, sobre um suposto esquema de lavagem de dinheiro e fraude fiscal que Renous disse que permitiu a Gaydamak lavar dinheiro de armas. (Chittum, 2015, p.4)
\end{abstract}

Pressão da sociedade civil se refere aos posicionamentos e discursos de representantes da sociedade civil, sejam legisladores ou organizações de classes ou ONGs que solicitam ações do governo no sentido de fornecer explicações e/ou coibir brechas legais e jurídicas que permitem a ocorrência de crimes e fraudes envolvendo o mercado financeiro:

Robert Barrington, diretor executivo da Transparency International UK, disse que as revelações do The Guardian sobre o papel do Reino Unido no crime financeiro não devem "surpreender ninguém". "Um ano depois dos Panama Papers, podemos ver que os supervisores antilavagem de dinheiro estão dormindo no trabalho, os bancos têm sido, no mínimo, negligentes e, na pior das hipóteses, cúmplices, e as agências de segurança do Reino Unido têm um histórico sombrio de investigações que levam a processos judiciais. Basicamente, as defesas contra lavagem de dinheiro do Reino Unido simplesmente não são adequadas para o propósito. O governo precisa de uma estratégia de classe mundial para lidar com isso, se vai convencer as pessoas de que não estamos em uma corrida pós-Brexit para o ponto em que o dinheiro corrupto é recebido de braços abertos no Reino Unido." (Hopkins et al., 2017, p.2)

O tema disrupção é identificado como potencial contraponto à questão da impunidade. Nesse sentido, por mais que sejam muitos e complexos os desafios impostos por essa "nova" colonialidade, é importante criar espaços de resistência (Banerjee \& Linstead, 2001), como as delações, as reportagens investigativas de jornalistas independentes e a atuação de atores, políticos ou não, que declaram seus posicionamentos de protesto. Entretanto, dificuldades como a insegurança dos delatores precisam ser superadas e, ao mesmo tempo, instituições como os consórcios investigativos precisam conseguir se estabelecer como rede, fornecendo incentivo a expansão dessa forma de jornalismo em outras localidades, para que, como sugerido por Prasad (2003), sejam mais vozes criando e ocupando fissuras no discurso do poder dominante.

\title{
Discussão
}

Nos documentos analisados nesta pesquisa, identificamos padrões e atores na dinâmica dos esquemas de corrupção, o que sugere que a corrupção transnacional se diferencia do fenômeno local pela magnitude, complexidade e impunidade dos participantes (Sung, 2009), podendo ser definida como a corrupção que cruza as fronteiras, envolve agentes corporativos e governamentais e, por meio de sofisticados esquemas, drenam as riquezas de diversos países (Sung, 2005; Ware, \& Noone, 2005). 
Portanto, a corrupção transnacional é inteligível apenas em seu contexto social (Osoba, 1996).

A crítica pós-colonial nos orientou a examinar as questões de poder, economia e política presentes no envolvimento do setor financeiro em esquemas de corrupção. A dinâmica dos esquemas de corrupção transnacional funciona com práticas e projetos que sustentam e autorizam a construção de concepções universalistas (Vázquez-Arroyo, 2008). Como ocorre, por exemplo, em relação aos fluxos de capital entre países e ao conceito de desenvolvimento sustentado na globalização (Banerjee \& Linstead, 2001).

Sob a perspectiva da crítica pós-colonial, os atores encontrados na análise podem ser agrupados entre aqueles que estão do lado do colonizador e os que representam os colonizados. No primeiro grupo, identificamos: (i) as próprias instituições financeiras e seus intermediários; (ii) os contraventores de todas as categorias citadas nas reportagens; (iii) a justiça negligente e limitada pelo sistema globalizado; e (iv) o poder político que, em todas as versões coloniais, sempre se encontrou subjugado pelo poder do capital. No segundo grupo, mais vulneráveis e com menor articulação na dinâmica da corrupção transnacional, estão todas as (v) vítimas e (vi) o jornalismo investigativo com seus informantes.

Em um interrogatório nos organismos supranacionais de controle e combate à corrupção, a partir da crítica pós-colonial (Prasad, 2016), vemos que a corrupção não é um fenômeno particular de países periféricos, pelo contrário, a ação de empresas e outros atores transnacionais nos esquemas de corrupção tornam esses países vítimas das consequências da corrupção (Batabyal \& Chowdhury, 2015). As lentes da crítica pós-colonial nos guiaram na análise do material empírico, permitindo o questionamento da narrativa de que a corrupção é um fenômeno nativo de países periféricos, e que as populações desses países são os únicos responsáveis pelo problema (Apata, 2018).

O primeiro tema final revelado foi a cumplicidade do capital transnacional, a qual é representada pelas corporações financeiras em conluio com os contraventores que se envolvem em esquemas corruptos. Neste estudo, a definição transnacional, associada à corrupção, não se refere apenas ao suborno que atravessa fronteiras, mas também aos crimes associados e indispensáveis e, em particular, à lavagem e dinheiro. A análise indicou uma séria de padrões de conivência, leniência e orientação pelo HSBC, bem como de outras instituições financeiras a clientes como elites corruptas de países do terceiro mundo, cartéis de drogas, traficantes de armas, terroristas, contrabandistas de diamantes de sangue e sonegadores fiscais. Associada a discursos evasivos e dissimulados, a cumplicidade corporativa é desvelada na violência exercida diretamente pelos criminosos, mas de forma indireta e menos explícita por essas corporações na contínua extração de benefícios econômicos a despeito da vida e dos direitos humanos, tal como discutido por Banerjee (2008a) sobre o necrocapitalismo e o poder de decidir sobre quem deve viver.

O segundo tema final foi a impunidade, a qual se expressa tanto pelo lado do colonizador, quanto pelo do colonizado. Pelo lado do colonizador, 
revelam-se padrões nos quais se manifestam restrições e falta de capacidade das autoridades para coibir a criminalidade que sustenta a corrupção transnacional que, algumas vezes, limita-se por uma proximidade política publicamente controversa. No outro lado da impunidade, encontram-se as vítimas da violência e da indiferença do colonizador em paralelo com a resistência, que é representada pela mídia investigativa e seus delatores; esses, se articulam e aproveitam do crescimento da tecnologia da informação e dos meios e comunicação de massa para expor, mesmo que ainda em poucos casos, tais esquemas. Nesse tema, revelam-se a ambivalência e a contradição do discurso colonial (Prasad, 2003), pois, ao mesmo tempo em que aqueles no papel de colonizadores conclamam ao combate à criminalidade, articulam-se para limitá-lo.

O crime e a corrupção global estão interconectados, visto que atividades como o contrabando, tráfico de armas e drogas, terrorismo e evasão fiscal seriam impraticáveis sem o envolvimento corrupto de funcionários nas alfândegas, nas agências financeiras ou nos prestadores de serviço (Christensen, 2011; Sampson, 2010; Shelley, 2005), bem como sem instituições financeiras e redes de intermediários que estruturassem as operações de lavagem do dinheiro e ocultação do patrimônio (Christensen, 2011; Cooley; Sharman, 2015; Platt, 2017). Com base nessa perspectiva da corrupção transnacional, situamos o caso do envolvimento do HSBC como um intermediário que viabiliza transações ao mesmo tempo que conecta e orienta seus clientes no contexto pós-colonial.

Especificamente, sobre o HSBC, observou-se um padrão histórico de leniência e conivência com criminosos, com diversos processos acusatórios encerrados com acordos, resumidos às multas que, por maiores que fossem em relação às práticas da justiça até então, não representavam sanções que inibissem as eventuais reincidências. As recorrências foram acompanhadas de alegações de desconhecimento ou de que essas falhas já haviam sido regularizadas. Coerentes com a busca de lucratividade, interesse primordial dos negócios, e salvaguardadas pelo poder adquirido ao se tornarem sistemicamente importantes, grandes corporações, como o HSBC, representam a "espada do comércio" (Banerjee, 2008a, p.1546), embora menos visível hoje que nos dias do império, mas com o mesmo lastro de desapropriação da soberania e de miséria pelos territórios subjugados.

As mesmas práticas, as mesmas alegações de inocência e a mesma ausência das autoridades são constatações que, sob a lente pós-colonial proposta nesta pesquisa, desvelam a cumplicidade com o capital e a impunidade das grandes corporações em cada um desses eventos. Os benefícios da corrupção estão de um lado e as consequências, de outro, visto que a instituição bancária que lucra com as transações financeiras é britânica e os principais paraísos ficais utilizado para ocultar os pagamentos também estão no Norte Global, como os territórios britânicos, Suíça, EUA e Hong Kong. Do outro lado, estão as vítimas, sejam elas dos cartéis de droga Latino-americanos, de governos corruptos ou traficantes no Oriente Médio, África e Leste Europeu. Essa polaridade enseja uma das interrogações centrais da crítica pós-colonial sobre as teorias do progresso e da modernidade (Elam, 2019; Prasad, 2016; Vázquez-Arroyo, 2008). 
A teoria pós-colonial dirige uma crítica radical ao colonialismo, imperialismo e o neocolonialismo (Banerjee \& Prasad, 2008). A crítica pós-colonial, ao examinar questões de poder, economia, política, religião e cultura, e como esses elementos funcionam em relação ao controle da hegemonia colonial dos ocidentais sobre os colonizados, faz um interrogatório crítico das práticas, modalidades e projetos pelos quais a modernidade se inseriu e alterou as vidas dos colonizados. Trata-se de um movimento que prioriza o questionamento sistemático das suposições epistêmicas e políticas que sustentaram e autorizaram a construção das concepções universalistas (Vázquez-Arroyo, 2008).

Corporações multinacionais associadas a governantes, organismos supranacionais e agências internacionais contribuem para a violenta privatização da soberania, sobrepondo seus interesses econômicos, atrelados ao poder militar que já caracterizava o projeto colonial, sob uma nova configuração imperialista e neoliberal (Banerjee, 2008ª Scott, 1999). Essas formas contemporâneas de acumulação organizacional, muitas vezes, com a conivência das elites políticas locais, "envolvem espoliação e subjugação da vida ao poder da morte" (Banerjee, 2008a, p.1541), caracterizando um necrocapitalismo, exemplificado na violência de indústrias extrativistas em países periféricos e na privatização da guerra, dos conflitos armados e da segurança.

Este artigo concorda com os autores da revisão da literatura que afirmam que os estudos que buscam explicar a predominância da corrupção em algumas regiões do mundo, apesar de considerarem seu impacto para o desenvolvimento econômico e político desses países, ignoram o papel do colonialismo na sua formação e institucionalização, ou seja, o projeto colonial continua a definir e construir economias e nações (Watson, 2016). É essencial que se reconheçam essas relações coloniais, identificando o poder das dinâmicas de cumplicidade de corporações globalizadas com o crime internacional, bem como a dinâmica da impunidade decorrente da relação conflituosa estabelecida entre o poder do capital e do poder político. Dessa maneira, acreditamos que, ao reconhecerem os interesses presente nessas relações, pesquisadores possam analisar as propostas e os discursos anticorrupção a partir de uma subjetividade mais próxima às margens, gerando, assim, alternativas coerentes com a perspectiva dos colonizados e, talvez, mais factíveis com a realidade e necessidade desses territórios.

\section{Considerações finais}

Este estudo procurou contribuir ao apresentar teorias sobre a dinâmica da corrupção transnacional, seus padrões e atores sob uma perspectiva crítica que contextualiza esse fenômeno com articulações mais amplas, como um "novo" poder colonial globalizado que se manifesta na contradição da cumplicidade de alguns e da impunidade de outros. Como resultado desta pesquisa, reconhecemos, como proposto por Banerjee (2008a) ao discorrer sobre o necrocapitalismo, que o imperialismo e o colonialismo sustentam, historicamente, a expansão do capitalismo, formal ou informalmente, por meio da dominação e exploração de territórios. Nesse sentido, a crítica 
pós-colonial possibilita desvelar as relações estabelecidas entre nações, instituições, agências e corporações transnacionais, nas quais conceitos de fronteira e território são transgredidos a despeito de qualquer noção de independência (Banerjee, 2008a; Costa, 2013; Prasad, 2003;), ficando a "soberania política subserviente à soberania econômica da corporação" (Medeiros, 2015, p. 207).

As limitações da pesquisa incluem a quantidade de documentos analisados, uma vez que limitamos a análise temática às reportagens em websites gratuitos por questões de operacionalização da pesquisa. Outros documentos e publicações podem ampliar as categorias identificadas.

Quanto às implicações teóricas da pesquisa, apontamos que a adoção das lentes do pós-colonialismo para o estudo da corrupção contribui para a discussão do assunto como um fenômeno associado a várias dimensões implícitas, como as relações que emergem em um contexto impregnado pelo projeto colonial, em que corporações transnacionais, cujo controle acionário estão em países do Norte, agem com impunidade, deixando, desse modo, a população dos países do Sul como vítimas. Especificamente, nós contribuímos para o conhecimento conceitual sobre corrupção transnacional nos estudos organizacionais, conduzindo uma pesquisa em um contexto pouco estudado. Ademais, buscamos desvelar as relações coloniais, identificando a dinâmica de cumplicidade de corporações globalizadas que lucram com a subjugação da soberania das nações periféricas e, muitas vezes, da vida, bem como da dinâmica da impunidade conferida pela proximidade do poder do capital e do poder político. Dessa maneira, acreditamos que, ao reconhecerem os interesses presente nessas relações, os pesquisadores podem analisar as propostas e os discursos hegemônicos anticorrupção a partir de uma subjetividade mais próxima às margens, gerando, assim, alternativas coerentes com a perspectiva dos colonizados. Ainda, ao assumir a lente da crítica pós-colonial nesta pesquisa, vislumbramos a possiblidade e a urgência de construir conhecimento a partir da periferia, mudando as perspectivas universalistas dominantes.

O campo irá se beneficiar de pesquisas sobre corrupção transnacional que se utilizem de outras fontes, como processos concluídos ou em andamento, por exemplo, pois tais fontes podem eventualmente contribuir com novas categorias ou atores que não foram identificados. Sugerimos ainda pesquisas que incorporem a intertextualidade, ou seja, que incluam no corpus outras reportagens referenciadas por meio de hiperlinks nos textos já selecionados.

\section{Referências}

Adler, P. S., Forbes, L. C., \& Willmott, H. (2007). Critical management studies. The Academy of management annals, 1(1), 119-179.

Almeida, J., Miglievich-Ribeiro, A., \& Gomes, H. T. (2013). Crítica pós-colonial: panorama de leituras contemporâneas. Rio de Janeiro: 7 Letras.

Alvesson, M., \& Deetz, S. (1999). Teoria crítica e abordagens pós-modernas para estudos organizacionais. In S. R. Clegg, C. Hard \& W. R. Nord (Orgs.). Handbook de estudos organizacionais: modelos de análise e novas questões em estudos organizacionais, (Vol. 1, Cap. 8, pp. 227-266). São Paulo: Atlas. 
Anand, V., Ashforth, B. E., \& Joshi, M. (2004). Business as usual: the acceptance and perpetuation of corruption in organizations. Academy of Management Executive, 18(2), 1-16.

Apata, G. O. (2018). Corruption and the postocolonial state: how the west invented African corruption. Journal of Contemporary African Studies, 36(1), 43-56.

Ashcroft, B., Griffiths, G., \& Tiffin, H (2003). Introduction. In B. Ashcroft, G. Griffiths \& $\mathrm{H}$. Tiffin. The empire writes back: theory and practice in post-colonial literatures. (Vol. 1, pp. 1-13). London: Routledge.

Ashfort, B. E, \& Anand, V. (2003). The normalization of corruption in organizations. Research in Organizational Behavior, 25(1), 1-52.

Banerjee, S. B., \& Linstead, S. (2001). Globalization, multiculturalism and other fictions: colonialism for the new millennium? Organization, 8(4), 683-722.

Banerjee, S. B. (2008a). Necrocaptalism. Organization Studies, 29(12), 1541-1563.

Banerjee, S. B. (2008b). Corporate social responsibility: the good, the bad and the ugly. Critical sociology, 34(1), 51-79.

Banerjee, S.B., \& Prasad, A. (2008), Introduction to the special issue on 'Critical reflections on management and organizations: a postcolonial perspective'. Critical perspectives on international business, 4(2/3), 90-98.

Batabyal, S., \& Chowdhury, A. (2015). Curbing corruption, financial development and income inequality. Progress in Development Studies, 15(1), 49-72.

Bauer, M. W., \& Aarts, B. (2002). A construção do corpus: um princípio para a coleta de dados qualitativos. In: M. W. Bauer \& G. Gaskell (Orgs.). Pesquisa qualitativa com texto, imagem e som: um manual prático. (Cap. 2, pp. 39-63). Petrópolis: Editora Vozes.

Bratsis, P. (2014). Political corruption in the age of transnational capitalism: from the relative autonomy of the state to the White Man's Burden. Historical Materialism, 22(1), 105-128.

Braun, V., \& Clarke, V. (2006). Using thematic analysis in psychology. Qualitative Research in Psychology, 3(2), 77-101.

Campos, J. E., Lien, D., \& Pradhan, S. (1999). The impact of corruption on investment: predictability matters. World Development, 27(6), 1059-1067.

Carrington, P. D. (2007). Law and transnational corruption: the need for Lincoln's law abroad. Law \& Contemporary Problems, 70(4), 109-138.

Carlin, A. \& Lokanan, M. E. (2018). Ritualisation and money laundering in the Swiss banking sector. Journal of Money Laundering Control, 21(1), 89-103.

Chittum, R. (2015). Diamond dealers in deep trouble as bank documents shine light on secret ways. IClJ. Recuperado em 14 maio, 2018, de https://www.icij.org/ investigations/swiss-leaks/diamond-dealers-deep-trouble-bank-documents-shinelight-secret-ways/.

Christensen, J. (2011). The looting continues: tax havens and corruption. Critical Perspectives on International Business, 7(2), 177-196.

Coronado, G. (2008) Discourses of anti-corruption in Mexico. Culture of corruption or corruption of culture? Journal of Multidisciplinary International Studies, 5(1), 1-23. 
Cooley, A. \& Sharman, J. C. (2015) Blurring the line between licit and illicit: transnational corruption networks in Central Asia and beyond. Central Asian Survey, 34(1), 11-28.

Cooley, A. \& Sharman, J. C. (2017). Transnational corruption and the globalized individual. Perspectives on Politics, 15(3), 732-753.

Costa, S. (2013). (Re)Encontrando-se nas redes? As ciências humanas e a nova geopolítica do conhecimento. In J. Almeida, A. Miglievich-Ribeiro \& H. T. Gomes (Orgs.). Crítica pós-colonial: panorama de leituras contemporâneas. Rio de Janeiro: 7Letras.

Dart, T. (2016). Families of Americans killed by Mexican cartels sue HSBC for laundering billions. The Guardian. Recuperado em 05 junho, 2018, de https://www.theguardian.com/business/2016/feb/11/families-of-americans-killedby-mexican-cartels-sue-hsbc.

Davies, R. (2017). HSBC 'complicit' in South Africa scandal, House of Lords told. The Guardian. Recuperado em 04 junho, 2018, de https://www.theguardian.com/ business/2017/nov/01/hsbc-investigated-fund-transfers-south-africa-corruptionrow-zuma-gupta.

De Klerk, J. J. (2017). "The Devil Made Me Do It!" An inquiry into the unconscious "Devils Within" of rationalized corruption. Journal of Management Inquiry, 26(3), 254-269.

De Maria, B. (2008). Neo-colonialism through measurement: a critique of the corruption perception index. Critical perspectives on international business, 4(2/3), 184-202.

De Maria, W. (2005, julho). The new war on African "corruption": just another neo-colonial adventure. 4th International Critical Management Studies Conference. Cambridge University, Cambridge, UK (pp. 2-21).

Dion, M. (2013). Uncertainties and presumptions about corruption. Social Responsibility Journal, 9(3), 412-426.

Elam, J. D. (2019). Postcolonial Theory. Literary and Critical Theory. Recuperado em 10 março, 2019, de https://www.oxfordbibliographies.com/view/document/ obo-9780190221911/obo-9780190221911-0069.xml. DOI: 10.1093/ OBO/9780190221911-0069

Farrel, P. et al. (2015) Leading Australian figures held offshore bank accounts. The Guardian. Recuperado em 04 junho, 2018, de https://www.theguardian.com/ news/2015/feb/09/hsbc-swiss-files-leading-australian-figures-held-offshore-bankaccounts?CMP=share_btn_tw.

Fitzgibbon, W, \& Hamilton, M. M. (2015). Bank's services for arms dealers in conflict with its own policy. ICIJ. Recuperado em 14 maio, 2018, de https://www.icij.org/ investigations/swiss-leaks/banks-services-arms-dealers-conflict-its-own-policy/.

Fitzgibbon, W, \& Hamilton, M. M. (2016) law firm's files include dozens of companies and people blacklisted by U.S. authorities. ICIJ. Recuperado em 04 junho, 2018, de https://www.icij.org/investigations/panama-papers/20160404-sanctionedblacklisted-offshore-clients.

Freitas Júnior, L. R., \& Medeiros, C. R. O. (2018). Estratégias de racionalização da corrupção nas organizações: uma análise das declarações de acusados em casos de corrupção no Brasil. Revista de Ciências da Administração, 20(50), 8-23. 
Garside, J. (2015). HSBC pays out £28m over money-laundering claims. The Guardian. Recuperado em 05 junho, 2018, de https://www.theguardian.com/ business/2015/jun/04/hsbc-fined-278m-over-money-laundering-claims.

Global Witness (2015). Banks and dirt money: how the financial system enables States looting at a devastating human cost. Recuperado em 26 junho, 2018, de https://www.globalwitness.org/en/campaigns/corruption-and-money-laundering/ banks-.

Gupta, A. (1995). Blurred boundaries: the discourse of corruption, the culture of politics, and the imagined state. American Ethnologist, 22(2), 375-402.

Gupta, A., Nugent, D., \& Sreenath, S. (2015). State, corruption, postcoloniality: a conversation with Akhil Gupta on the 20th anniversary of "Blurred Boundaries". American Ethnologist, 42(4), 581-591. DOI: https://doi.org/10.1111/amet.12157

Hamilton, M. M. (2015). Whistleblower? Thief? Hero? Introducing the source of the data that shook HSBC. ICIJ. Recuperado em 14 maio, 2018, de https://www.icij.org/ investigations/swiss-leaks/whistleblower-thief-hero-introducing-source-data-shookhsbc/.

Harding, L., Hopkins, N., \& Barr, C. (2017). British banks handled vast sums of laundered Russian money. The Guardian. Recuperado em 11 junho, 2018, de https:// www.theguardian.com/world/2017/mar/20/british-banks-handled-vast-sums-oflaundered-russian-money.

Hardouin, P. (2017). Too big to fail, too big to jail: restoring liability a lesson from HSBC case. Journal of Financial Crime, 24(4), 513-519.

Hopkins, N., Harding, L., \& Mason, R. (2017). Police to examine 'Global Laundromat' money laundering allegations. The Guardian. Recuperado em 13 junho, 2018, de https://www.theguardian.com/world/2017/mar/21/police-to-examine-globallaundromat-money-laundering-allegations.

Huntington, S. (1975). Political order in changing societies. New Haven: Yale U. Press. ICIJ (2016). Giant leak of offshore financial records exposes global array of crime and corruption. ICIJ. Recuperado em 04 junho, 2018, de https://www.icij.org/ investigations/panama-papers/20160403-panama-papers-global-overview/.

ICIJ (2017). Explore the Panama papers key figures. ICIJ. Recuperado em 31 janeiro, 2017, de https://www.icij.org/investigations/panama-papers/explore-panamapapers-key-figures/.

Krippendorf, K. (2004). Content analysis. An introduction to its methodology. Thousand Oaks: Sage.

Lambsdorff, J.G., \& Schulze, G. G. (2015). What can we know about corruption? A very short history of corruption research and a list of what we should aim for. Journal of Economics and Statistics, 235(2), 100-114.

Leigh, D., Ball, J., Garside, J., \& Pegg, D. (2015a). HSBC's response: 'Standards of due diligence were significantly lower than today'. The Guardian. Recuperado em 04 junho, 2018, de: https://www.theguardian.com/business/2015/feb/08/hsbcresponds-revelations-misconduct-swiss-bank

Leigh, D. et al. (2015b). HSBC files: Catalogue of malpractice endorsed by bankers laid bare in HSBC files. The Guardian. Recuperado em 04 junho, 2018, de https:// www.theguardian.com/business/2015/feb/08/hsbc-files-catalogue-malpracticebankers-tax?CMP=share_btn_tw. 
Leigh, D. et al. (2015c). Cash pilgrims and bricks of money: HSBC Swiss bank operated like cash machine for rich clients. The Guardian. Recuperado em 04 junho, 2018, de https://www.theguardian.com/business/2015/feb/09/hsbc-files-swissbank-cash-machine-rich-clients?CMP=share_btn_tw.

Leigh, D. et al. (2015d). Swiss bank aggressively pushed way for clients to avoid new tax. The Guardian. Recuperado em 05 junho, 2018, de https://www.theguardian. com/business/2015/feb/10/hsbc-files-swiss-bank-aggressive-marketing-clientsavoid-new-tax.

Leigh, D. et al. (2015e). HSBC files show Tories raised over £5m from HSBC Swiss account holders. The Guardian. Recuperado em 05 junho, 2018, de: https://www. theguardian.com/business/2015/feb/11/hsbc-files-show-tories-raised-over-5mfrom-hsbc-swiss-account-holders.

Leigh, D. et al. (2015f). Fugitives, aides and bagmen: HSBC's 'politically exposed' clients. The Guardian. The Guardian. Recuperado em 05 junho, 2018, de: https:// www.theguardian.com/news/2015/feb/12/hsbc-politically-exposed-clientsfugitives-aides-bagmen.

Lord, N. J. (2014). Responding to transnational corporate bribery using international frameworks for enforcement: Anti-bribery and corruption in the UK and Germany. Criminology \& Criminal Justice, 14(1), 100-120.

Mathiason, N. (2010). HSBC accused of aiding 'unusual' Angolan \$50m money transfer. The Guardian. Recuperado em 04 junho, 2018, de https://www.theguardian. com/business/2010/feb/04/hsbc-angola-us-senate.

Mathiason, N., \& Barr, C. (2011) HSBC under fire over leading role in land deals for Mubarak regime. The Guardian. Recuperado em 05 junho, 2018, de https://www. theguardian.com/business/2011/may/01/hsbc-egypt-corruption-mubarak-.

Medeiros, C. R. O. (2013) Inimigos públicos: crimes corporativos e necrocorporações. Tese de Doutorado, Fundação Getúlio Vargas, São Paulo, SP, Brasil. DOI: https://doi. org/10.1590/S0034-759020150209

Medeiros, C. R. O. (2015). Crimes corporativos e estudos organizacionais: uma aproximação possível e necessária. Revista de Administração de Empresas, 55(2), 202-208.

Montigny, P. (2015). Is corruption a cultural issue? Ethic Inteligence. Recuperado em 08 junho, 2017, de http://www.ethic-intelligence.com/blog/8291-corruptioncultural-issue/.

Mulinge, M. M., \& Lesetedi, G. N. (1998). Interrogating our past: colonialism and corruption in Sub-Saharan Africa. African Journal of Political Science, 3(2) 15-28.

Neate, R., \& Treanor, J. (2016). FBI arrests senior HSBC banker accused of rigging multibillion-dollar deal. The Guardian. Recuperado em 05 junho, 2018, de https:// www.theguardian.com/business/2016/jul/20/hsbc-mark-johnson-stuart-scottarrested-currency-exchange.

OECD - Organization for Economic Co-Operation and Development (2017). Fighting the crime of foreign bribery: the anti-bribery convention and the OECD working group on bribery. Recuperado em 23 março, 2018, de http://www.oecd.org/corruption/ Fighting-the-crime-of-foreign-bribery.pdf. 
Osoba, S. O. (1996). Corruption in Nigeria: historical perspectives. Review of African Political Economy, 23(69), 371-386.

Pinto, C. (2011). A banalidade da corrupção: uma forma de governar o Brasil. Belo Horizonte: Editora UFMG

Platt, S. (2017). Criminal capital. How the finance industry facilitates crime. London: Palgrave Macmillan.

Prasad, A. (2003). Postcolonial theory and organizational analysis: a critical engagement. New York: Springer. DOI: https://doi.org/10.1057/9781403982292

Prasad, A. (2016). Toward decolonizing modern Western structures of knowledge. A Postcolonial interrogation of (Critical) Management Studies. In P. Prasad, A. Prasad, A. J. Mills \& J. Helms Mills (Eds.). The Routledge Companion to Critical Management Studies. (pp. 161-199) London: Routledge.

Pratley, N. (2015). HSBC's Presbyterian principles forgotten in the global dash for cash. The Guardian. Recuperado em 04 junho, 2018, de https://www.theguardian. com/business/nils-pratley-on-finance/2015/feb/09/hsbcs-presbyterian-principlesforgotten-in-the-global-dash-for-cash.

Rose-Ackerman, S. (1996). Democracy and 'grand' corruption. International Social Science Journal, 48(149), 365-380.

Rose-Ackerman, S. (2002). "Grand" corruption and the ethics of global business. Journal of Banking \& Finance, 26, 1889-1918.

Ryle, G., Fitzgibbon, W., Cabra, M., Carvajal, R., Guevara, M. W., Hamilton, M. M., \& Stites, T. (2015). Banking giant HSBC sheltered murky cash linked to dictators and arms dealers. ICIJ. Recuperado em 14 maio, 2018, de https://www.icij.org/ investigations/swiss-leaks/banking-giant-hsbc-sheltered-murky-cash-linkeddictators-and-arms-dealers/.

Rushe, D. \& Treanor, J. (2012). HSBC's record \$1.9bn fine preferable to prosecution, US authorities insist. The Guardian. Recuperado em 05 junho, 2018, de https://www. theguardian.com/business/2012/dec/11/hsbc-fine-prosecution-money-.

Sampson, S. (2010). The anti-corruption industry: from movement to institution. Global Crime, 11(2), 261-278.

Scott, D. (1999). Refashioning futures. Criticism after Postcoloniality. Princeton: Priceton University Press.

Shelley, L. (2005) The unholy trinity: transnational crime, corruption, and terrorism. Brown Journal of World Affairs, 11(2), 101-111.

Sikka, P. (2008). Enterprise culture and accountancy firms: new masters of the universe. Accounting, Auditing \& Accountability Journal, 21(2), 268-295.

Sikka, P. (2010). Smoke and mirrors: corporate social responsibility and tax avoidance. Accounting Forum, 34(3-4) 153-168.

Sikka, P. \& Lehman, G. (2015). The supply-side of corruption and limits to preventing corruption within government procurement and constructing ethical subjects. Critical Perspectives on Accounting, 28, 62-70.

Silbey, S. S. (1997). 1996 Presidential address: "Let them eat cake": globalization, postmodern colonialism, and the possibilities of justice. Law and Society Review, 31(2), 207-235. 
Silva, M. (1994) Corrupção: tentativa de uma definição funcional. Revista de Administração Pública, 28(1), 18-23.

Smith, E. B., \& Babcock, C. R. (2015). New law, new loophole, new business for giant global bank HSBC. ICIJ. Recuperado em 14 maio, 2018, de https://www.icij. org/investigations/swiss-leaks/new-law-new-loophole-new-business-giant-globalbank-hsbc/.

Spivak, G. C. (1988). Can the subaltern speak? In C. Nelson \& L. Grossberg (Eds.). Marxism and the Interpretation of Culture (pp. 271-313). Chicago: Chicago Press.

Sung, H. E. (2005). Between demand and supply: bribery in international trade. Crime, Law and Social Change, 44(1), 111-132.

Sung, H. E. (2009). Transnational corruption in weapons procurement in East Asia: a case analysis. Sociological Focus, 42(3) 254-275.

Transparency International. (2009). Global Corruption Report 2009: corruption and the private sector. Cambridge University Press, United Kingdom. Recuperado em 25 abril, 2018, de https://www.transparency.org/whatwedo/publication/global_ corruption_report_2009.

Treanor, J. (2014). Foreign exchange fines: banks handed £2.6bn in penalties for market rigging. (12/11/2014). The Guardian. Recuperado em 05 junho, 2018, de https://www.theguardian.com/business/2014/nov/12/foreign-exchange-fines-ubshsbc-citibank-jp-morgan-rbs-penalties-market-rigging.

Tuckett, A. (2005). Applying Thematic Analysis Theory to practice: a researcher's experience. Contemporary Nurse, 19(1-2), 75-87. DOI: https://doi.org/10.5172/ conu.19.1-2.75.

United Nation Office on Drugs and Crime (2004). United Nation Convention against corruption. General Assembly resolution 58/4 of 31 October 2003. Vienna, Austria. Recuperado em 15 outubro, 2017, de https://www.unodc.org/documents/treaties/ UNCAC/Publications/Convention/08-50026_E.pdf

Vázquez-Arroyo, A. Y. (2008). Universal history disavowed: on critical theory and postcolonialism. Postcolonial Studies, 11(4), 451-473. DOI: $10.1080 / 13688790802468288$

Ware, G. T. \& Noone, G. P. (2005). The anatomy of transnational corruption. International Affairs Review, 14(2), 29-51.

Watson, I. (2016). First nations and the colonial project. Inter Gentes, 1(1), 30-49.

Williams, J. W. \& Beare, M. E. (1999). The business of bribery: globalization, economic liberalization, and the "problem" of corruption. Crime, Law \& Social Change, 32(2), 115-146.

Witsoe, J. (2011). Corruption as power: caste and the political imagination of the postcolonial state. Journal of the American Ethnological Society, 38(1), 73-85.

World Bank Group. Worldwide Governance Indicators. Recuperado em 06 junho, 2017, de http://info.worldbank.org/governance/wgi/index.aspx\#reports.

World Bank Independent Evaluation Group (2006). Annual Report. Recuperado em 10 junho, 2019, de https://documents.worldbank.org/en/publication/documentsreports/documentdetail/420691468336684389/independent-evaluation-groupmiga-2006-annual-report. 